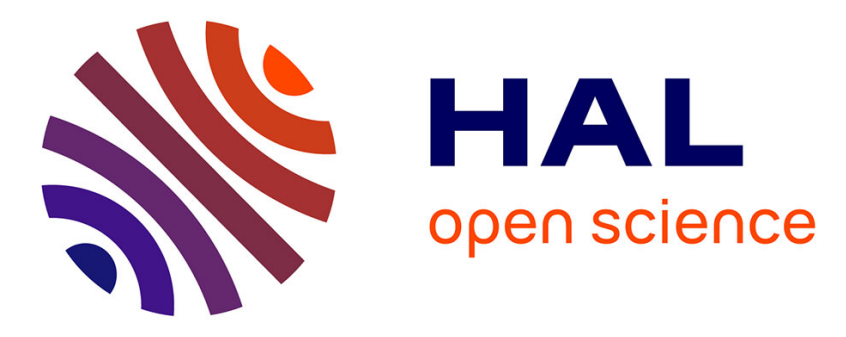

\title{
Dating of rockfall damage in trees yields insights into meteorological triggers of process activity in the French Alps
}

Robin Mainieri, Christophe Corona, Julien Chartoire, Nicolas Eckert, Jérôme Lopez Saez, Stoffel Markus, Franck Bourrier

\section{To cite this version:}

Robin Mainieri, Christophe Corona, Julien Chartoire, Nicolas Eckert, Jérôme Lopez Saez, et al.. Dating of rockfall damage in trees yields insights into meteorological triggers of process activity in the French Alps. Earth Surface Processes and Landforms, 2020, 45 (10), pp.2235-2250. 10.1002/esp.4876 . hal-03129920

\section{HAL Id: hal-03129920 \\ https://hal.science/hal-03129920}

Submitted on 9 Aug 2021

HAL is a multi-disciplinary open access archive for the deposit and dissemination of scientific research documents, whether they are published or not. The documents may come from teaching and research institutions in France or abroad, or from public or private research centers.
L'archive ouverte pluridisciplinaire HAL, est destinée au dépôt et à la diffusion de documents scientifiques de niveau recherche, publiés ou non, émanant des établissements d'enseignement et de recherche français ou étrangers, des laboratoires publics ou privés. 


\title{
Dating of rockfall damage in trees yields insights into meteorological triggers of process activity in the French Alps
}

\author{
R. Mainieri ${ }^{*}$, C. Corona ${ }^{2}$, J. Chartoire ${ }^{3}$, N. Eckert ${ }^{3}$, J. Lopez-Saez ${ }^{4,5}$, M. Stoffe ${ }^{4,5,6}$ and F. Bourrier ${ }^{3}$ \\ 1 Université Grenoble Alpes, INRAE, UR LESSEM, 2 rue de la Papeterie-BP 76, St-Martin-d'H'eres F-38400, France \\ 2 Maison des sciences de l'homme, GEOLAB, UMR6042 CNRS/Université Blaise Pascal, Clermont-Ferrand Cedex 2 63057, France \\ 3 Université Grenoble Alpes, INRAE, UR ETNA, 2 rue de la Papeterie-BP 76, St-Martin-d'H'eres F-38400, France \\ 4 Institute of Environmental Sciences - University of Geneva, 66 bd Carl Vogt, Carouge $\mathrm{CH}-1227$, Switzerland \\ 5 Dendrolab.ch, Department of Earth Sciences, University of Geneva, 13 rue des Maraîchers, Geneva CH-1205, Switzerland \\ 6 Department F.A. Forel for Environmental and Aquatic Sciences, University of Geneva, 66 Boulevard Carl-Vogt, Carouge CH-1227, \\ Switzerland
}

*Correspondence to: Robin Mainieri, Université Grenoble Alpes, INRAE, UR LESSEM, 2 rue de la Papeterie-BP 76, F-38400 St-Martin-d'H'eres, France. E-mail: robin. mainieri@inrae.fr

\begin{abstract}
Rockfall release is a rather unpredictable process. As a result, the occurrence of rockfall often threatens humans and (infra)structures. The assessment of potential drivers of rockfall activity therefore remains a major challenge, even if the relative influence of rainfall, snowmelt, or freeze-thaw cycles has long been identified in short-term monitoring projects. In the absence of longer-term assessments of rockfall triggers and possible changes thereof, our knowledge of rockfall dynamics remains still lacunary as a result of the persisting scarcity of exhaustive and precise rockfall databases. Over the last decades, several studies have employed growth disturbances (GDs) in tree-ring series to reconstruct rockfall activity. Paradoxically, these series were only rarely compared to meteorological records. In this study, we capitalize on the homogeneity of a centennial-old reforestation plot to develop two reconstructions - R1 including only growth suppressions, and R2 based on injuries - with limited biases related to decreasing sample size and changes in exposed diameters back in time. By doing so, our study also and quite clearly highlights the large potential that protection forests have in terms of yielding reliable, multidecadal rockfall reconstructions. From a methodological perspective, we find no synchronicity between R1 and R2, as well as an absence of meteorological controls on rockfall processes in R1. This observation pleads for a careful selection of GDs in future reconstructions. In terms of process dynamics, we demonstrate that summer intense rainfall events $\left(>10 \mathrm{~mm} \mathrm{day}^{-1}\right)$ are the main drivers for rockfall activity at our study site. Despite the stringency of our detection procedure, correlations between rockfall activity and meteorological variables remain comparable to those reported in previous studies, as a result of the complexity and multiplicity of triggering factors. We therefore call for a more systematic coupling of tree-ring analysis with rockfall and microclimatic monitoring in future studies.
\end{abstract}

KEYWORDS: rockfall; dendrogeomorphic analyses; snow and weather reanalyses; triggering factors; French Alps

\section{Introduction}

Rockfall is one of the most common geohazards on steep slopes and can lead to major economic losses and casualties (Hantz et al., 2003). The process involves the detachment and transport of independent blocks of relatively small sizes from a cliff: rockfall is characterized by high energy and mobility of fragments moving down slopes by gravity in a combination of free fall, bouncing, and rolling (Michoud et al., 2012; Sazid, 2019). Slope stability on slopes susceptible to produce rockfall is predominantly controlled by the presence, orientation, and geomechanical properties of discontinuities (Terzaghi, 1962). The actual triggering of rockfall is due either to external factors (Cruden and Varnes, 1996) such as earthquakes (Keefer, 2002; Malamud et al., 2004; Stoffel et al., 2019), volcanic eruptions
(Hale et al., 2009), sea waves (Rosser et al., 2005), or anthropogenic activities (Heim, 1931; Müller, 1964), whereas their temporal frequency is modulated by meteorological parameters (Delonca et al., 2014; D'Amato et al., 2016). Intense rainfall episodes (Rapp, 1960; André, 1997; Ilinca, 2009; Berti et al., 2012), freeze-thaw cycles of interstitial water (Wieczorek and Jäger, 1996; Matsuoka and Sakai, 1999; Ilinca, 2009; Dunlop, 2010), the thawing of permafrost (Huggel et al., 2012; Sass and Oberlechner, 2012; Stoffel and Huggel, 2012), or repeat rock surface temperature variations (Luckman, 1976; Gunzburger et al., 2005; Frayssines and Hantz, 2006) have thus been mentioned as the main triggering mechanisms of rockfall activity in the past. Yet, a large body of the above-mentioned studies were based on short-term field observations or monitoring. Even if such approaches provide very high-quality datasets 
(Matsuoka, 2008; D'Amato et al., 2016), they will not cover process activity on specific sites over continuous periods of several years and therefore have to be considered as too short for a precise assessment of the full spectrum of triggering factors and threshold conditions of rockfalls (Schneuwly and Stoffel, 2008b; Šilhán et al., 2011). By contrast, multidecadal series of past rockfall activity are typically gathered from historical archives (Hantz et al., 2003; Barnikel, 2004; Guzzetti and Tonelli, 2004; Delonca et al., 2014), but Guzzetti et al. (1999) pertinently emphasized that historical records are only rarely available and difficult to obtain for single events or event-prone areas. In addition, archival data remains usually fragmentary (Dussauge-Peisser et al., 2002), and records tend to contain information mainly on events that caused fatalities or the destruction of human assets, but will - in contrast - lack data on small-scale events and non-damageable activity. Such limitations have often precluded precise assessments of (meteorological) triggers of past rockfall activity (Sass and Oberlechner, 2012). On forested slopes, falling blocks interact with forest stands (Dorren et al., 2007) and may inflict scars and other growth anomalies on trees (Trappmann and Stoffel, 2015). The detection and dating of growth disturbances (GDs) in tree-ring series, also referred to as dendrogeomorphology (Alestalo, 1971; Stoffel and Bollschweiler, 2008; Stoffel and Corona, 2014), has been demonstrated to represent a reliable approach to (partly) overcome the gaps and limitations inherent in historical archives (Ibsen and Brunsden, 1996; Sass and Oberlechner, 2012). Limitations in the ability of tree-ring records to yield accurate representations of past rockfall activity at a site remain and can be ascribed to (1) the continuous reduction in the number of trees available for analysis and the total diameter of exposed trees as one goes back in time (Stoffel et al., 2005), (2) the associated decline of potentially recordable GDs (Trappmann et al., 2013), as well as (3) interferences induced by climate conditions or exogenous disturbances (Favillier et al., 2017a). The latter have been used successfully to compute the frequency of past rockfall events (Stoffel and Perret, 2006; Trappmann et al., 2014; Morel et al., 2015; Mainieri et al., 2019), and/or to map preferential trajectories or parameterize three-dimensional, process-based rockfall models (Stoffel et al., 2006; Corona et al., 2013, 2017). Yet, with the exception of Perret et al. (2006), Šilhán et al. (2011), and Zielonka and WrońskaWałach (2019), tree-ring reconstructions were only rarely compared with instrumental series to assess meteorological triggering parameters. In addition, the above studies have accounted for changing sample depths, but have considered neither any reductions of target size (i.e. smaller tree diameters) back in time, nor the potential influence of climatic conditions or exogenous disturbances (e.g. insect and pathogen attacks, windstorms or anthropogeneous influences) on dendrogeomorphic reconstructions. In order to account for the latter parameter, which could potentially bias the detection of meteorological triggers of rockfall, we (1) base this study on samples taken in a protection forest planted since the end of the 19th century, with the aim to minimize potential biases related to increasing sample size over time. In addition, we (2) used the systematic mapping of all trees within the plot to precisely quantify uncertainties related to the decrease of total stem diameter exposed to rockfalls over time. To evidence potential noise induced by climatic conditions or exogeneous signals, we then (3) realized two reconstructions, namely R1 including only growth suppression and R2 accounting for all other growth types of disturbances. Finally, we (4) compared the corrected rockfall activity with highly resolved time series of potential meteorological triggers extracted from the snow and meteorological reanalysis products available for France (Durand et al., 2009a, b).

\section{Study Site}

The study site is located at Valdrôme (146 inhabitants, Figure 1b), on a west-facing slope of the Arcs mountain $\left(44^{\circ} 32^{\prime} 90 \mathrm{~N}\right.$, 5³3'76 E, 790-880 m a.s.l.), Diois massif (French Alps, Figure 1a). At this site, rockfall fragments are detached from several release areas located within a roughly $40 \mathrm{~m}$-high, west-facing cliff (890-930 m a.s.l.). This Jurassic (Thitonian) cliff is composed of sublithographic limestone (Figure 1e) with a content of marls (5-6\%) characterized by narrow jointing, subhorizontal bedding, and subvertical orthogonal joints, favouring fragmentation and the release of small rock fragments with volumes ranging from a few cubic centimetres to a few cubic decimetres. In the field, the presence of recent scars in rock cliffs, fresh injuries on tree stems (in the form of bark scratches or wood-penetrating injuries), and fresh blocks (recognizable through the absence of lichens, mosses, or patina) deposited on the slope was used to verify the existence of current rockfall activity at the site (Moya et al., 2010; Trappmann and Stoffel, 2015). Down the cliff, the talus slope, with angles varying from 35 to $45^{\circ}\left(40^{\circ}\right.$ on average), is characterized by a marked longitudinal sorting of clasts with volumes of a few cubic centimetres at the apex to a few cubic decimetres in the distal segment. At an altitude of $730 \mathrm{~m}$ a.s.I., the talus slope is crossed by a road leading to Valdrome. At its lower end, the site is limited by the Drôme River (at 720 m a.s.l.). The 1.3 ha (110 × $115 \mathrm{~m}$ ) tree plot analysed here is located at the foot of the cliff (Figure $1 \mathrm{~d})$; it is covered by a dense (1800 trees ha $\left.{ }^{-1}\right)$ monospecific forest stand composed of Pinus nigra (Austrian black pine). Trees were planted at the beginning of the 20th century (1902) by the French forestry service with the aim of protecting the national road from rockfalls. According to the SAFRAN reanalysis (Durand et al., 2009b), total precipitation at the study site (1958-2017) totalled $1022( \pm 201) \mathrm{mm}$ on average; the driest season is winter $(182 \pm 172 \mathrm{~mm})$, whereas wetter conditions prevail in autumn $(339 \pm 143 \mathrm{~mm})$. Mean annual, winter, and spring temperatures average $10.2( \pm 0.6), 1.1( \pm 1.1)$, and 8.2 $( \pm 0.9){ }^{\circ} \mathrm{C}$, respectively (Figure $\left.1 \mathrm{c}\right)$. On average, $90( \pm 14)$ freeze-thaw cycles occurred each year at the study sites between 1958 and 2017, mainly during winter and spring $(85 \%)$. Although no event could be retrieved from historical archives, field observations (i.e. scars on stems, presence of impact craters on the ground) confirm that rockfall is the dominant geomorphic process on the slope and that other geomorphic processes susceptible to damage trees can be totally excluded.

\section{Methods}

\section{Tree plot}

At the study site, virtually all trees show visible growth anomalies on the stem surface resulting from past rockfall, predominantly in the form of injuries. As scars represent the most accurate and reliable GD to date past rockfalls in tree-ring records (Schneuwly et al., 2009a,b; Stoffel et al., 2013), we actively searched for visible stem wounds at the study site. To assess spatial and temporal patterns of past rockfall activity, trees with a diameter at breast height $(\mathrm{DBH})>4 \mathrm{~cm}$ were systematically mapped in a $110 \times 115 \mathrm{~m}$ large tree plot. The position of each tree $(n=1479)$ was determined $( \pm 100 \mathrm{~cm})$ with a theodolite measuring azimuth (compass), distance (vertex), and slope (inclinometer). All trees were positioned in a geographical information system (GIS) as geo-objects. The resulting map has been used to optimize our sampling strategy by (1) 

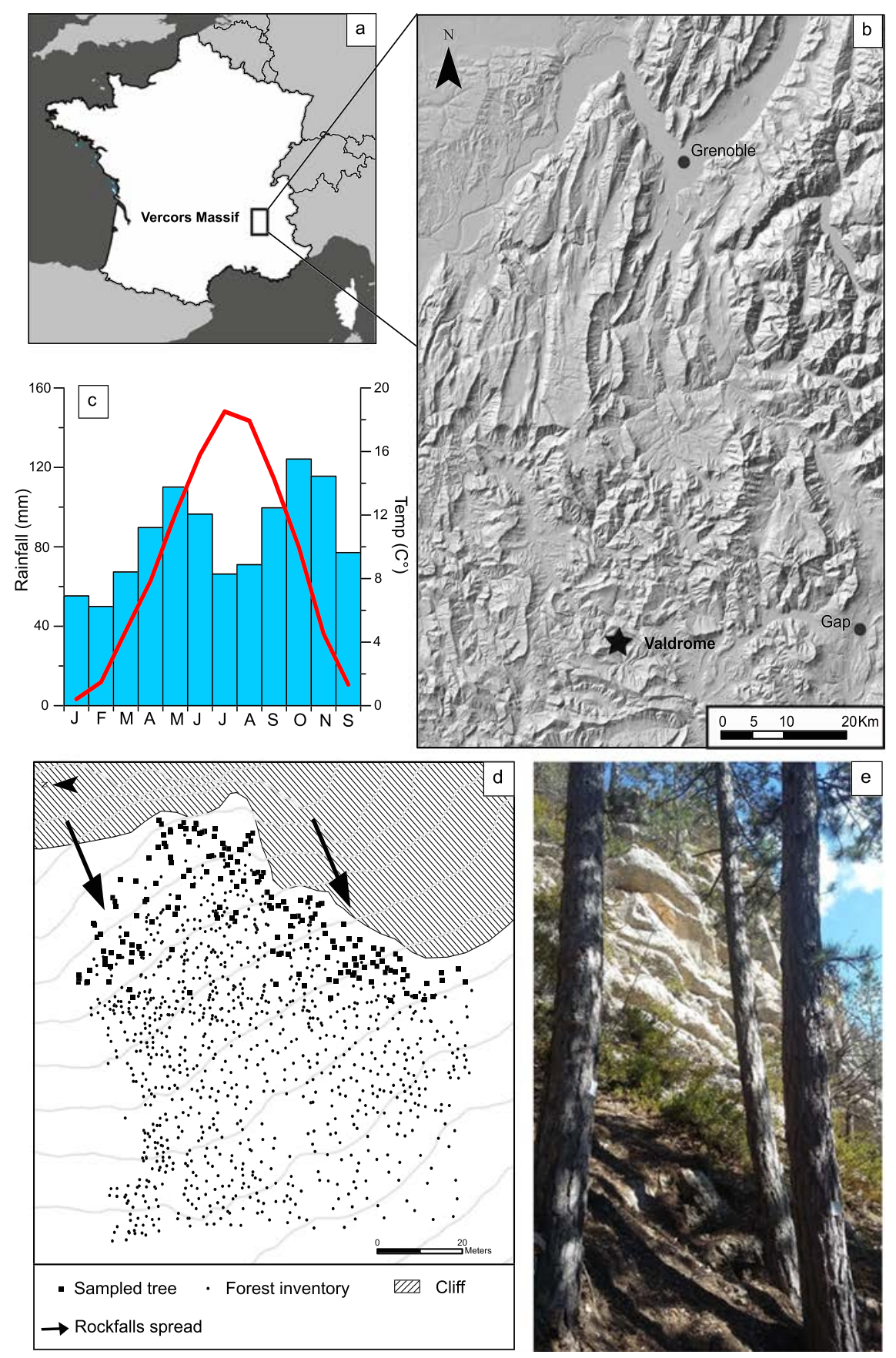

FIGURE 1. The Valdrôme plot is located in the Southern French Alps (a), $60 \mathrm{~km}$ south of Grenoble and $30 \mathrm{~km}$ west of Gap (b). It is characterized by mountainous climatic conditions with a mean annual temperature of $9.1 \pm 1.1{ }^{\circ} \mathrm{C}$ and precipitation totals of $1082 \mathrm{~mm}$ on average over the period 1958-2017 (c). At the study plot, 1479 trees were mapped at 1-m resolution, mainly Austrian black pines (P. nigra) that were planted at the turn of the 20th century (d, e). [Colour figure can be viewed at wileyonlinelibrary.com]

increasing the conditional impact probability and (2) selecting individual trees for each rockfall trajectory (see below).

\section{Computation of conditional impact probability}

The conditional impact probability approach (CIP), first developed by Moya et al. (2010), has recently been refined further by Trappmann et al. (2013) and Favillier et al. (2017b). This approach aims to quantify the range covered by trees during a given year, and is employed here to estimate the likelihood that a rockfall event misses tree trunks (Perret et al., 2006). The assessment depends on both the characteristics of the forest (i.e. stand density, tree location, tree diameter, spatial structure of the forest stand) and the characteristics of the rockfall event itself (diameter of the falling blocks). The CIP concept is based on the idea that each tree is surrounded by a 'circle of impact' (i.e. covering a range of the slope that determines the probability of a tree being impacted). A falling rock will impact a tree if its trajectory is closer to the stem than half of its diameter $(\varnothing)$. This 'circle of impact' can therefore be expressed as a circular area around each tree, with diameter defined by the tree's $\mathrm{DBH}$ and the mean diameter of falling blocks $(\varnothing)$. According to this principle, the sum of impact circles of all trees represents the total length of impact circles $\left(L_{I C}\right)$ or the range that is covered by trees (Figures 2a and b). Accordingly, with a given mean rock diameter, tree position, and the DBH measured for all trees, the CIP can be calculated for the plot as 


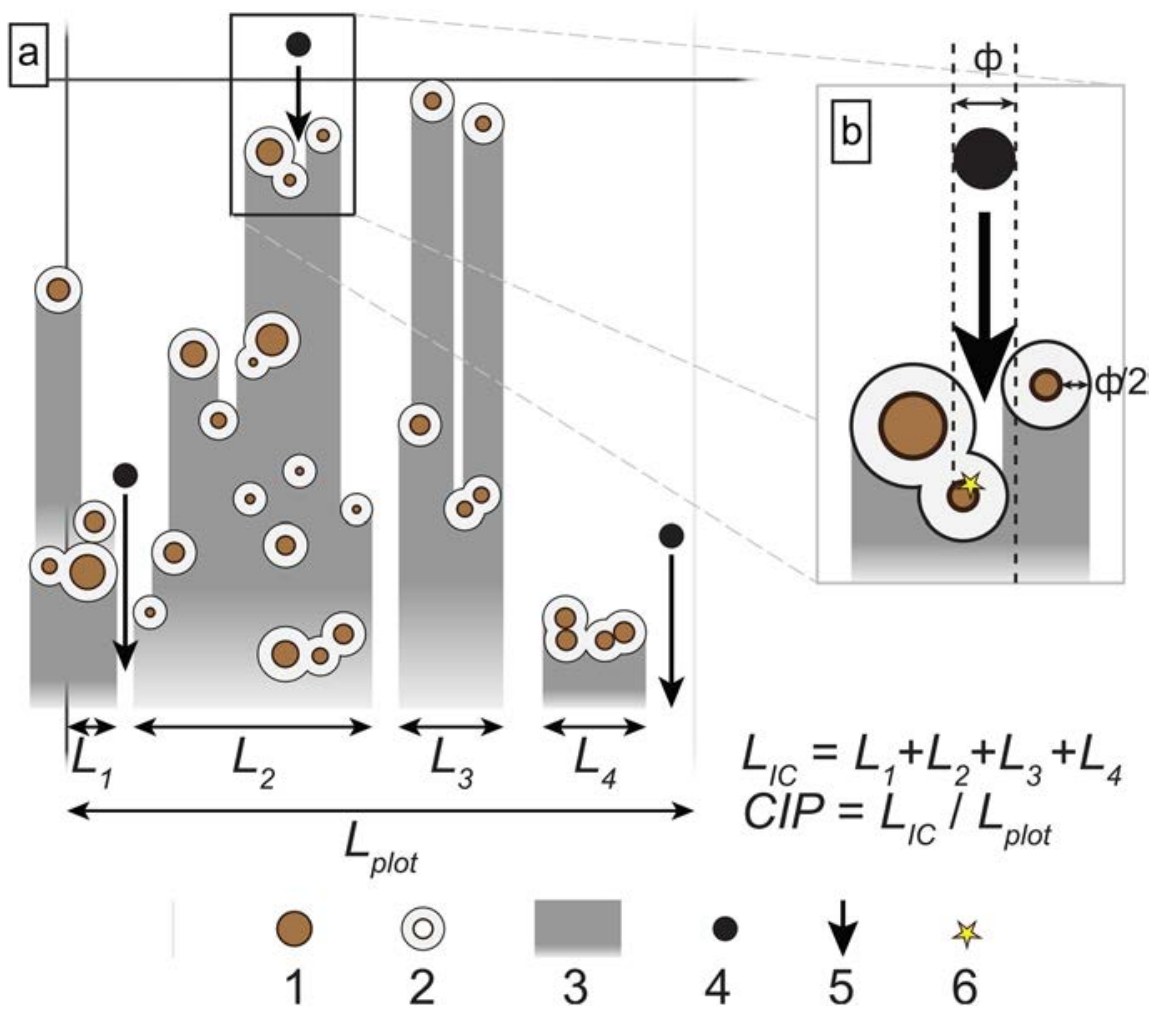

FIGURE 2. Geometrical conditions used for the assessment of the CIP adapted from Moya et al. (2010) and Favillier et al. (2017b). (a) Computation of the CIP from the geometric analysis of the spatial distribution of trees at the plot scale. (b) Computation of the impact circle: 1 , tree stem; 2 , circle of impact; 3 , projection of the circles of impact on the downslope boundary of the analysis cell; 4 , rock of a given diameter, denoted Ø; 5 , trajectory of the falling rock; 6 , rockfall impact. $L_{1}-L_{4}$ are the width of the projection of the circles of impact on the downslope boundary of the plot analysis. $L_{\text {plot }}$ is the width of the analysis cell. [Colour figure can be viewed at wileyonlinelibrary.com]

$$
\mathrm{CIP}=L_{I C} / L_{\text {plot }}
$$

where $L_{I C}$ is the cumulative length of the projections of the 'circles of impact' on the downslope side of the plot, and $L_{p l o t}$ is the length of the plot in the fall line (i.e. $110 \mathrm{~m}$ in our case).

Usually, the CIP is used to estimate the number of rockfall events that are missed (i.e. not recorded) in a given year as well as the quality and reliability of the reconstruction (Trappmann et al., 2013; Favillier et al., 2017b). Here, to quantify CIP evolution back in time, a polynomial diameter-age regression has been built for $P$. nigra. To this end, a total of 53 undisturbed $P$. nigra trees with $\mathrm{DBH}>5 \mathrm{~cm}$ were cored using a Pressler increment borer. Trees were selected from three stem diameter classes $(<8,8-18$, and $>18 \mathrm{~cm})$, representative of the distribution of tree diameters observed at the plot. Increment cores were analysed and data processed following standard dendrochronological procedures (Bräker, 2002). In the laboratory, tree rings were counted with a digital LINTAB positioning table connected to a Leica stereomicroscope. Missing rings toward the pith were estimated from ring curvature (Villalba and Veblen, 1997; Bollschweiler et al., 2008).

Based on this regression model, we estimated the age of each tree within the plot and derived an annually resolved CIP series, so as to estimate the real annual number of rockfalls (RR) as follows:

$$
\mathrm{RR}_{t}=\mathrm{NGD}_{t} / \mathrm{CIP}_{t}
$$

where $\mathrm{NGD}_{t}$ represents the number of GD dated to year $t$ and where $\mathrm{CIP}_{t}$ is the conditional probability impact computed for year $t$. In addition, based on our systematic inventory, we also used the CIP to optimize our sampling strategy. Accordingly, trees located in the upper part of the slope represent the first barrier to falling blocks; these were sampled preferentially, whereas those trees located in the direct fall line of other trees were ignored systematically as they would be protected by their neighbours.

\section{Dendrogeomorphic analysis and corrected number of impacts}

An increment core (max. $40 \times 0.5 \mathrm{~cm}$ ) was sampled for each selected tree at the lateral edges of each visible scar, at the contact with the overgrowing callus tissue (Sachs, 1991; Larson, 1994). In addition, based on observed bounce heights - which usually remain $<2 \mathrm{~m}$ in the plot - three additional increment cores were systematically extracted, in the fall line direction, at heights of $0.5,1.0$, and $1.5 \mathrm{~m}$, so as to increase the probability of retrieving evidence on old, completely healed impacts (Trappmann et al., 2013). Following Stoffel et al. (2005), (1) abrupt suppression of tree growth indicating decapitation or branch loss, (2) eccentric growth related to the formation of reaction wood following stem tilting, and (3) abrupt growth release (suggesting that neighbouring trees were eliminated and the surviving trees benefitted from improved growth conditions such as enhanced access to light, water and nutrients) were used as additional evidence of past rockfall impacts.

\section{Analysis of meteorological data}

The precise detection of meteorological triggers of rockfall from dendrogeomorphic reconstructions has so far been hampered by the annual resolution of tree-ring series as it precluded 
correlation with hourly and/or daily meteorological records. To account for the complexity and diversity of meteorological triggers, correlations between reconstructed rockfall activity and meteorological series averaged over resolutions comprised between 1 and 36 ( $\sim 1$ year) consecutive 10-day periods. At our study site, meteorological time series were obtained from the SAFRAN reanalysis datasets reaching back to the year 1958 . The SAFRAN analysis system combines in-situ meteorological observations with synoptic-scale meteorological fields to provide continuous time series of meteorological variables at hourly resolution and for elevation steps of $300 \mathrm{~m}$ within areas referred to as massifs ('Devoluy' in the case of this study), assumed to be horizontally homogeneous (Durand et al., 2009a). Delonca et al. (2014) and D'Amato et al. (2016) have recently synthesized physical processes associated with meteorological parameters susceptible to trigger rockfall. In calcareous regions, these authors listed the following processes amongst the most frequently cited triggers of rockfall: (1) rainfall duration and intensities that increase pressure in rock joints, (2) freeze-thaw cycles through wedging and loss of cohesion, and (3) sunshine affecting thermal stresses, thereby propagating cracks. On this basis, and considering typical timeframes operating on these triggers, 10-day to annual series (i.e. 360 days; or 36,10 -day series) of (1) precipitation sums, (2) number of rainfall events $>10$ and $20 \mathrm{~mm} \mathrm{day}^{-1}$, (3) minimum, (4) mean, and (5) maximum air temperatures, (6) variations thereof, (7) the absolute number of freeze-thaw cycles (defined as the number of days in which $T_{\max }>0{ }^{\circ} \mathrm{C}$ and $T_{\min }<0{ }^{\circ} \mathrm{C}$ ), as well as (8) minimum temperatures $\left(-3\right.$ and $\left.-5{ }^{\circ} \mathrm{C}\right)$ and (9) daily variations of temperatures $\left(+6\right.$ and $+10^{\circ} \mathrm{C}$ ) have been extracted from the SAFRAN database for the period 1958-2017. Relationships between rockfall activity and meteorological parameters were assessed with a four-step procedure. In a first step (1), Pearson correlation coefficients were calculated between reconstructed rockfall activity and variables (1-9) for periods ranging from 1 to 36 consecutive 10-day periods. All datasets were transformed to $z$-scores summarizing anomalies below or above average, over the period 1958-2017, before correlation analyses were performed. The statistical significance of results was tested with a one-tailed $t$-test at a significance level $\alpha=0.05$. In a second step (2), up to 10 variables - those most strongly correlated with rockfall activity at a significance level $\alpha=0.05$ - were extracted for each meteorological parameter. Correlation matrices computed for each parameter were used to select the variables included in the multiple regression procedure (3), while limiting the inclusion of highly collinear variables. We developed a stepwise regression procedure to determine which combination of independent variables affect rockfall activity in the studied area. Starting from an initial null model with no covariates and then comparing the explanatory power of incrementally larger and smaller models, this procedure combines forward selection and backward elimination of variables using the Akaike information criterion (AIC) as a metric to compare the relative quality of the different models. Forward selection tests all the variables retained at step 2 , one by one, and includes them in the final selection if they are statistically significant based on the $p$ value of the $t$-statistics, whereas backward elimination starts with all candidate variables and tests them one by one for statistical significance, deleting those that are not significant on the basis of the $p$ value of the $t$-statistics. Model performance was evaluated with several indicators, such as the AIC and the adjusted- $R^{2}$ determination coefficient. The variance inflation factor (VIF), representing the quotient of the variance in a model with multiple terms by the variance of a model with one term alone, was used to quantify the severity of multicollinearity between predictor variables included in the model. Finally (4), based on z-score transformed reconstructions, we differentiated three levels of rockfall activity classified as low $(<-1 z$-score), medium $(1>z$-score $>-1)$ and high $(>1$ $z$-score). We used one-way analysis of variance (ANOVA) to determine the significance of differences between mean values of meteorological factors included in the multiple regression model. Snedecor's F-distribution was used to compare meteorological factor averages for the different levels of rockfall activity and within the same group.

\section{Results}

\section{Selection of sampled trees}

In the field, 30 deposited blocks with non-weathered surfaces and lacking moss or lichen cover were measured to determine characteristic block sizes involved in rockfall activity. Based on this inventory, a median block diameter $(\varnothing)$ of $30 \mathrm{~cm}$ has been defined for the calculation of the CIP. On the basis of this median block diameter, data on stem $\mathrm{DBH}$, as well as on the spatial position of each tree within the plot, we obtain a maximum CIP of 0.88 for 2018 based on the analysis of 179 trees. In other words, this means that as little as 179 trees - out of the 1479 mapped inside the plot - will intercept $91 \%$ of all rockfall trajectories at the site. All these trees (with a mean DBH of $24 \pm$ $9.6 \mathrm{~cm}$ ) were sampled to characterize past rockfall activity at Valdrôme. The 672 increment cores that we extracted at DBH indicate that trees were on average $106 \pm 13$ years old. The oldest tree was dated back to 1891, whereas the youngest tree reached sampling height in 1967 . The distribution of tree ages and the fairly limited standard deviation can be explained with the installation of the protection forest, described in historical archives, at the turn of the 20th century.

\section{Reconstruction of rockfall activity}

The sampled cores allowed identification of 532 and 434 GD in the tree-ring series for the periods 1890-2017 and 19582017, respectively (Table 1 ). The most common GD was in the form of abrupt growth suppression (GS, $66 \%$ of all GD). Injuries $(31.4 \%)$ represent another common response of $P$. nigra to rockfall impacts. By contrast, growth releases (GR) and the onset of compression wood $(\mathrm{CW})$ formation were identified in only 13 (2.4\% of the GDs for the period 1890-2017) and 1 tree $(<1 \%, 1958-2017)$, respectively. The oldest GD identified in the tree-ring series was dated to 1905. GD are more frequent after 1930 and nearly every year exhibited GD in at least a small number of trees.

Based on these GD series, two reconstructions of past rockfall activity have been computed. The first reconstruction (called R1) only includes GS recorded in tree-ring series (Figures $3 \mathrm{a}$ and $\mathrm{b}$ ). On average, the annual number of GS reached 4.1 over the period 1890-2017. The largest numbers of GS are observed in 1948 (38 GDs), 1949 (18), 2001 (18),

Table 1. Overview of growth distrubances found in the tree-ring series

\begin{tabular}{lrr}
\hline GD type & No. & Percentage \\
\hline Growth suppression (GS) & 351 & 66.0 \\
Injury & 167 & 31.4 \\
Growth release (GR) & 13 & 2.4 \\
Compression wood (CW) & 1 & 0.2 \\
Total & 532 & 100.0 \\
\hline
\end{tabular}



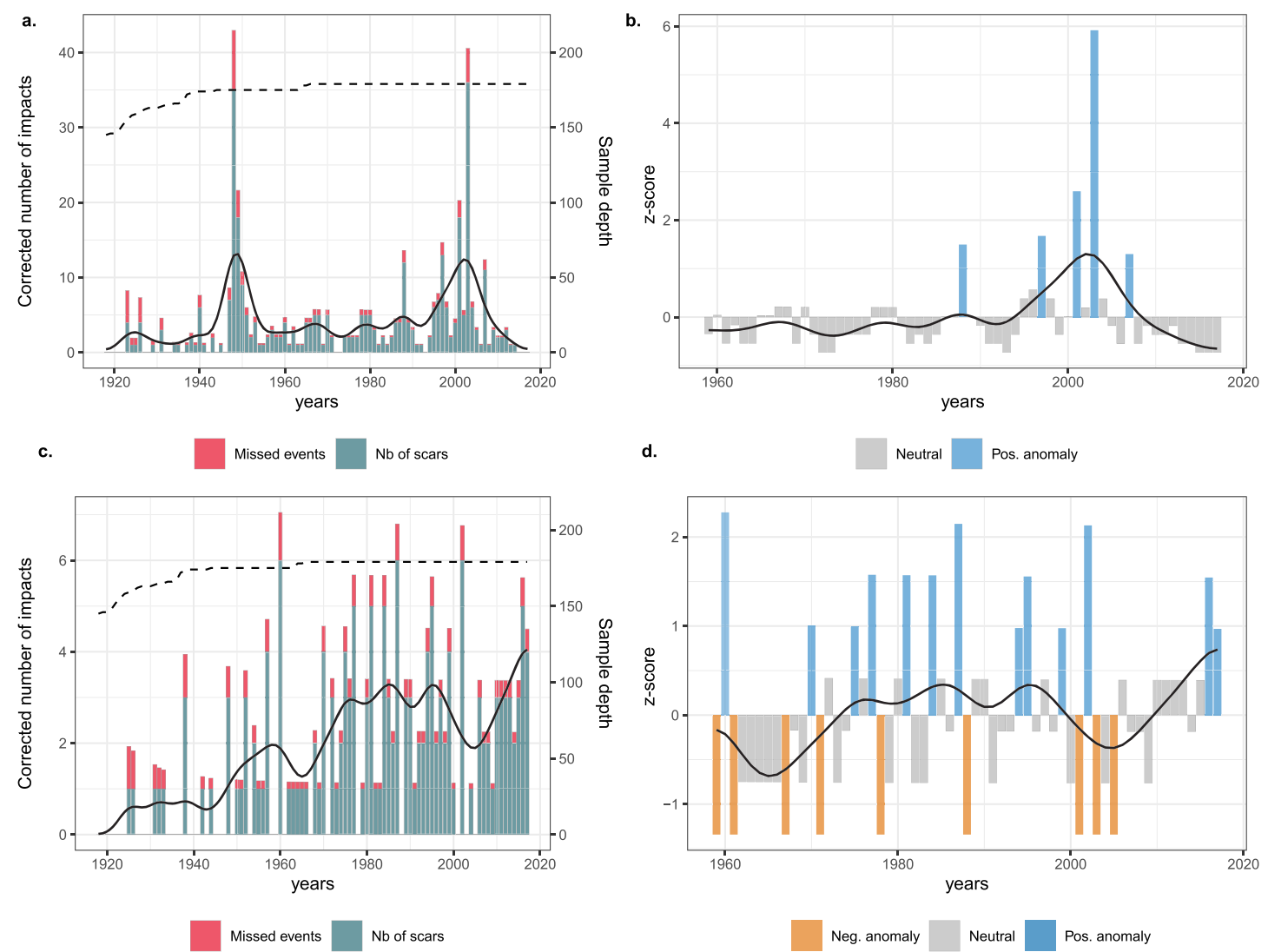

d.

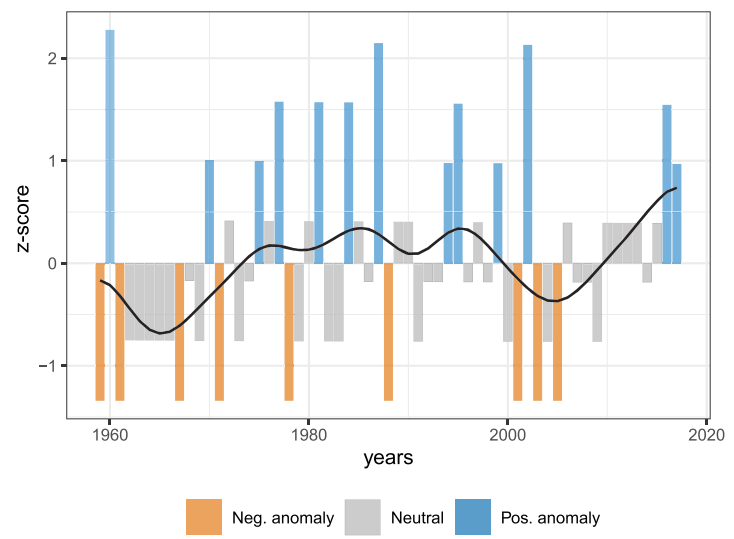

FIGURE 3. Reconstruction R1 ( $\mathrm{a}$, b; based on growth suppression, upper panel) and R2 (c, d; based on other growth disturbances, lower panel), expressed as the manual corrected number of impacts per year (a, c) and as Z-scores computed over the 1958-2017 periods (b, d). [Colour figure can be viewed at wileyonlinelibrary.com]

2003 (36), and 2007 (15). For the period 1930-2017, characterized by continuous rockfall activity, the decadal frequency of GS is largest between 2000 and 2009 (10.7 events year ${ }^{-1}$ ), whereas the smallest frequency is computed between 1930 and 1939 (1.5 events year $\left.{ }^{-1}\right)$. At the multidecadal scale, no clear trend could be identified in the GS series. The second reconstruction included only GD other than GS. As a consequence, 354 GS were excluded from the second reconstruction (called R2) (Figures 3a and b). According to this restricted dataset, 1.38 events occurred each year over the period 1890-2017, and a clear trend exists in the reconstruction as decadal frequencies increase from 0.6 events year $^{-1}$ in 1930-1939 to 3.2 events year $^{-1}$ in 2010-2017. Since 1958 (i.e. the beginning of meteorological series), 2.34 events were, on average, retrieved each year from the tree-ring series. The decades 1960-1969 (1.4 events year ${ }^{-1}$ ) and 2000-2009 (1.6 events year ${ }^{-1}$ ) are characterized by the lowest frequencies of impact. By contrast, rockfall activity increased to 2.8 events year ${ }^{-1}$ between 1975 and 2000. Maximum annual frequencies of impacts were recorded in 1960 (6 injuries), 1977 (5), 1981 (5), 1984 (5), 1995 (5), and 2002 (6). Conversely, no injuries could be retrieved with dendrogeomorphic analyses for 1958-9, 1967, 1971, 1988, 2001, 2003, and 2005. Interestingly as well, reconstructions R1 and R2 are not significantly correlated $(r=0.08, p>0.05)$ between each other over the period 1958-2017, and injuries were missing completely in several of the years characterized by a large number of GS (1949, 1988, 2001, and 2003).

\section{Estimation of missed events using the CIP approach}

Three diameter classes dominate among the $P$. nigra trees found within the plot, namely $<8,8-18$, and $>18 \mathrm{~cm}$. As most trees at the site were planted at the turn of the 20th century, one may assume that differences in diameters result from differences in local conditions such as competition, soil, or rockfall activity. As a consequence, three diameter-age regression models were developed for the $P$. nigra trees at Valdrôme as a function of diameter, as given by the following equations:

$$
\begin{gathered}
\operatorname{Age}_{t}=-0.0049\left(D_{t}\right)^{2}+1.37\left(D_{t}\right)+7.78(\text { diam }>18 \mathrm{~cm}, \\
\left.n=14 ; r^{2}=0.87 ; p<0.001\right)
\end{gathered}
$$

$$
\begin{gathered}
\operatorname{Age}_{t}=-0.0102\left(D_{t}\right)^{2}+1.95\left(D_{t}\right)+12.05(\text { diam } 8-18 \mathrm{~cm} \\
\left.n=24 ; r^{2}=0.81 ; p<0.001\right) \\
\mathrm{Age}_{t}=-0.0729\left(D_{t}\right)^{2}+4.75\left(D_{t}\right)+6.93(\text { diam }<8 \mathrm{~cm} \\
\left.\quad n=14 ; r^{2}=0.93 ; p<0.001\right)
\end{gathered}
$$

where $\mathrm{Age}_{t}$ represents the estimated age for each tree $(t)$, and $D_{t}$ represents the diameter of tree $t$. Based on these models and for a mean block diameter of $30 \mathrm{~cm}$, the CIP exceeded the 0.5 threshold - proposed by Trappmann et al. (2013) based on empirical considerations - for reliable reconstructions in 1924 (0.52). For the period 1958-2017 covered by the meteorological series, the CIP increased continuously from 0.85 to 0.88 . We adjusted both rockfall reconstructions (R1, R2) according to Equation (2), so as to account for missing events: in total, 51 and 24 rockfall events were missed over the period 19582017 in R1 and R2, respectively. After the CIP correction, the largest number of potential events are observed in 1988 (14), 
2003 (41), 2007 (17) in R1, and in 1960 (7), 1987 (7), 2002 (7) in R2 (Figure 3c). After transformation into $z$-scores (Figures 3c and d), 5 years $(1988,1997,2001,2003,2007)$ were found with high rockfall activity in R1. In the case of R2, 9 (1959, 1961, 1967, 1971, 1978, 1988, 2001, 2003, 2005) and 13 (1960, 1970, 1975, 1977, 1981, 1984, 1987, 1994, 1995, $1999,2002,2016,2017)$ years were classified with low and high rockfall activity, respectively. Interestingly, 1997, 2001, and especially 2003 - all pointing to extremely frequent GS in R1 - are characterized by a nearly complete absence of injuries in $\mathrm{R} 2$.

\section{Correlations between rockfall activity and meteorological co-variables}

Over the period 1958-2017 covered by meteorological records, correlations between rockfalls as reconstructed in R1 and 10-day to annual variables are synthesized in Figure 4. Weak $r$ values $(r>0.38, p<0.001)$ were computed between

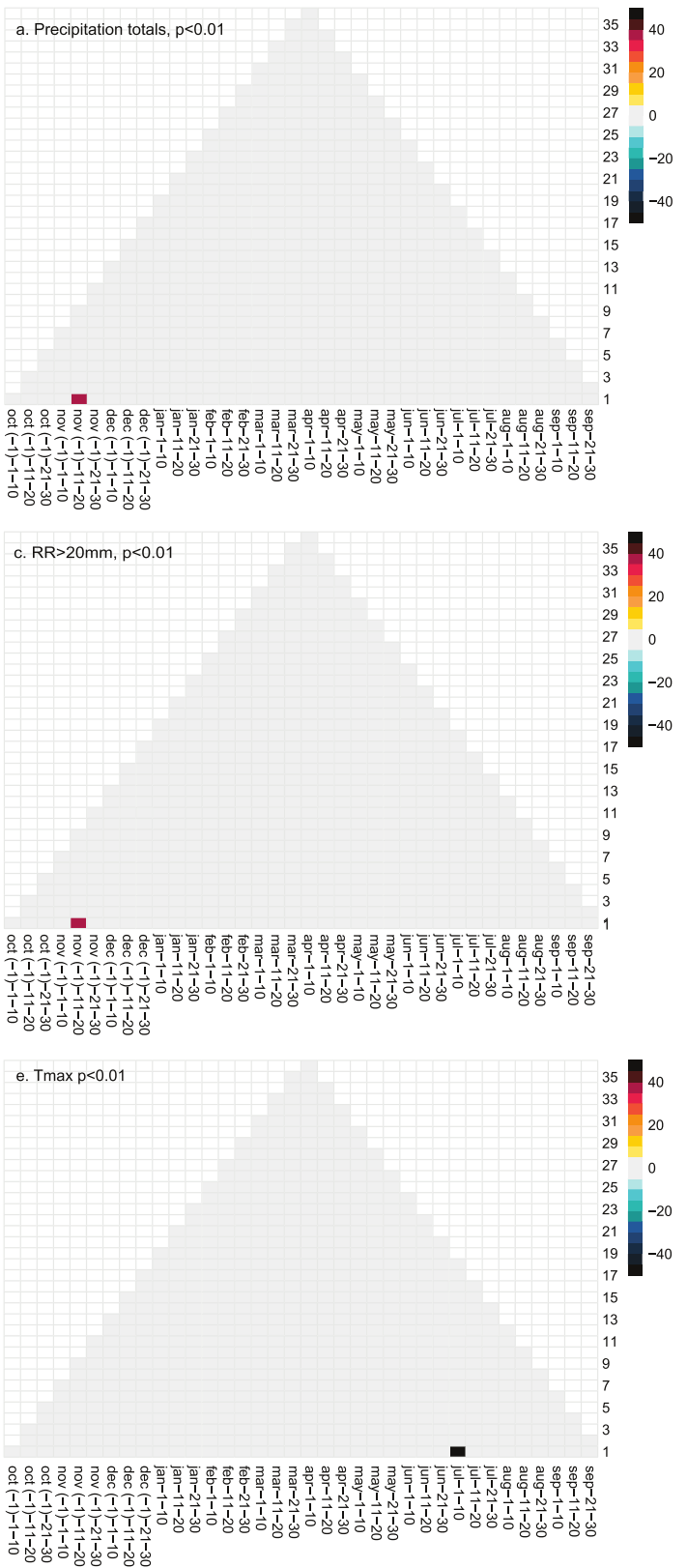

GS records and precipitation totals for the time window of November 11-20 in the year preceding the rockfall event $(n-1)$ (Figure 4a). Comparable correlations were retrieved between $\mathrm{R} 1$ and the number of very heavy $\left(\mathrm{RR}_{20}, p>20 \mathrm{~mm}\right)$ precipitation events during early autumn of year $n-1$ (Figures $4 \mathrm{~b}$ and c). Similarly, R1 is only positively $(r=0.46,0.43, p<0.01)$ correlated with mean and maximum temperatures over early July (i.e. July 1-10; Figures $4 \mathrm{~d}$ and e). Significant correlations were detected neither with minimal temperatures, temperature variations, or freeze-thaw cycle series, nor with meteorological records aggregated over more than 10 days. Similarly, we were unable to observe a unique pattern during the extreme years of 1988, 1997, 2001, 2003, or 2007 during which above-average frequencies were observed in the occurrence of GS (Figure 5): above-average precipitations were observed in 1988 (Figure 5a) and 2001 (Figure 5e), whereas dry conditions prevailed in spring and summer 2003 (Figure 5g). Similarly, the heatwave of spring and summer 2003 is clearly visible in Figure 5h, whereas negative temperature anomalies were observed during the growing season of 1997 (Figure 5d).

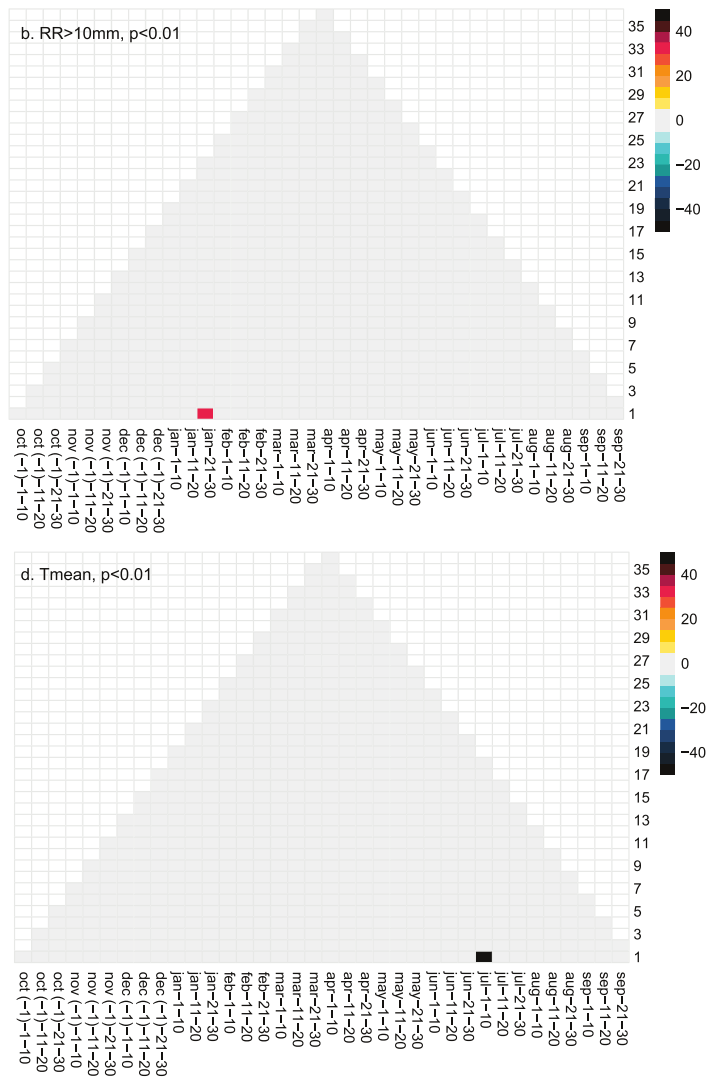

FIGURE 4. Correlations between R1 (reconstruction including only GS) and metereological covariables computed over 1 to 36 consecutive 10 -day periods. [Colour figure can be viewed at wileyonlinelibrary.com] 


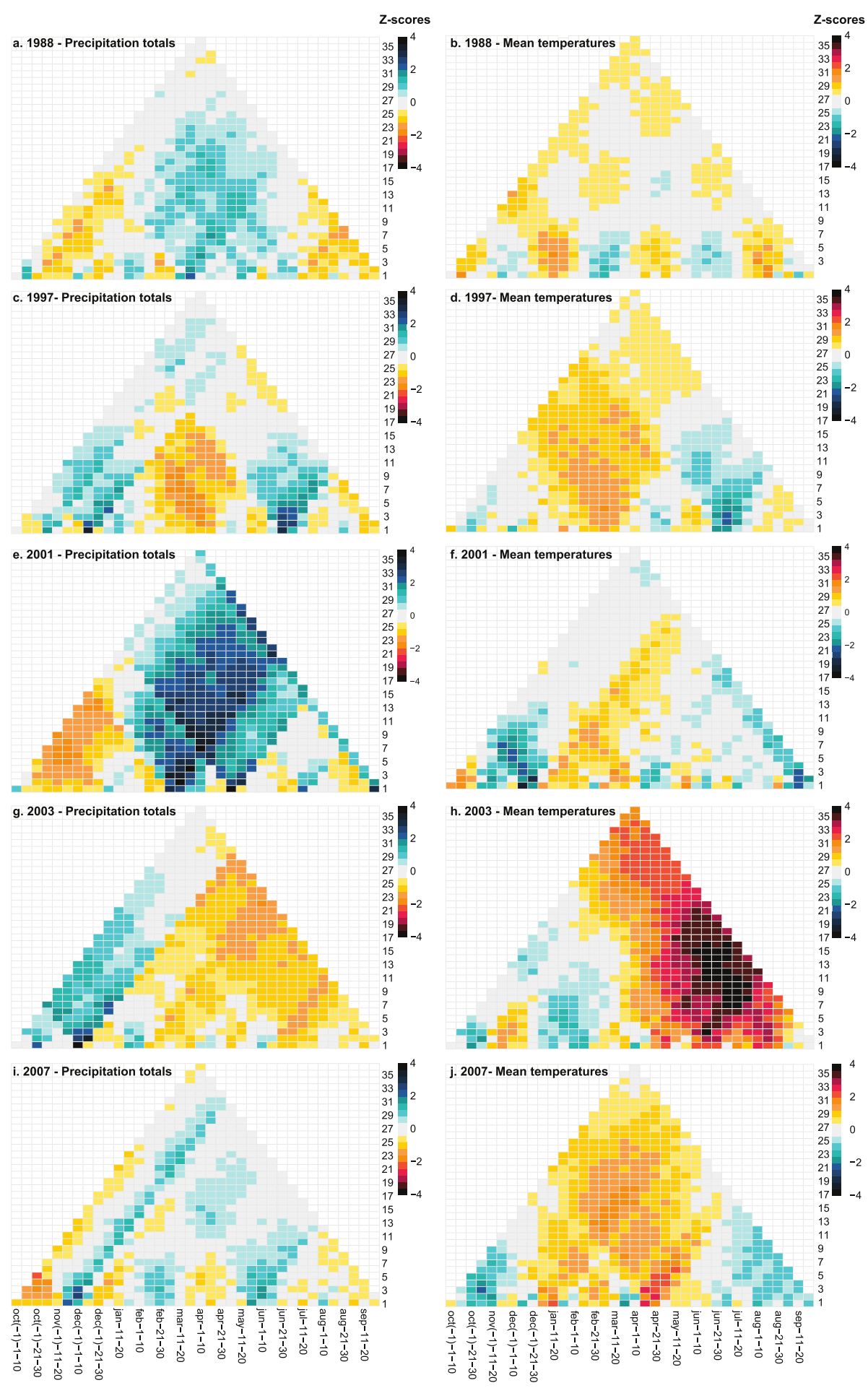

FIGURE 5. Correlation between R1, precipitation (left panel) and temperature (right panel) anomalies (z-scores) observed in 1988 (a, b), 1997 (c, d), $2001(\mathrm{e}, \mathrm{f}), 2003(\mathrm{~g}, \mathrm{~h})$, and $2007(\mathrm{i}, \mathrm{j})$. These years are characterized by extremely large numbers of growth suppressions detected in R1. [Colour figure can be viewed at wileyonlinelibrary.com]

Interestingly, the correlation matrices differ largely as soon as GS are removed from the reconstructions. With respect to precipitation totals, reconstruction R2 is positively and significantly $(p<0.01)$ correlated with precipitation totals during the growing season $(n)$, computed from 10 (September 11-20) to 150 days (centred on July $1-15$ ) (Figure 6a). The highest correlation coefficient $(r=0.49, p<0.001)$ is computed between R2 and precipitation totals (1958-2017) over a 30-day window centred on September 1-10. Comparable patterns are observed between rockfall activity in $\mathrm{R} 2$ and the number of summer rainfall events $>10 \mathrm{~mm}\left(\mathrm{RR}_{10}\right.$, Figure $\left.6 \mathrm{~b}\right)$ and $>20 \mathrm{~mm}\left(\mathrm{RR}_{20}\right.$, Figure 6c). The number of rainfall events $>10 \mathrm{~mm}(r=0.43$, $p<0.001)$ and $>20 \mathrm{~mm}(r=0.46, p<0.001)$ computed over 30 days centred on September 1-10 are the parameter that is most highly correlated with R2. Lower, yet still significant, correlations are computed between $\mathrm{R} 2$ and rainfall intensities $\left(R_{10}, R_{20}\right)$ over longer time periods (24-36 consecutive 10 -day series). With regard to temperature, minimum temperatures and temperature variations appear as the most robust drivers of rockfall activity in reconstruction R2 (Figures 6d and e). Negative correlations (with $r$ values ranging between -0.4 and $-0.46, p<0.01$ ) have been computed between R2 and minimum temperatures over 100 and 200 days, centred on June $1-10$ in the first and July $21-30$ in the latter case; 


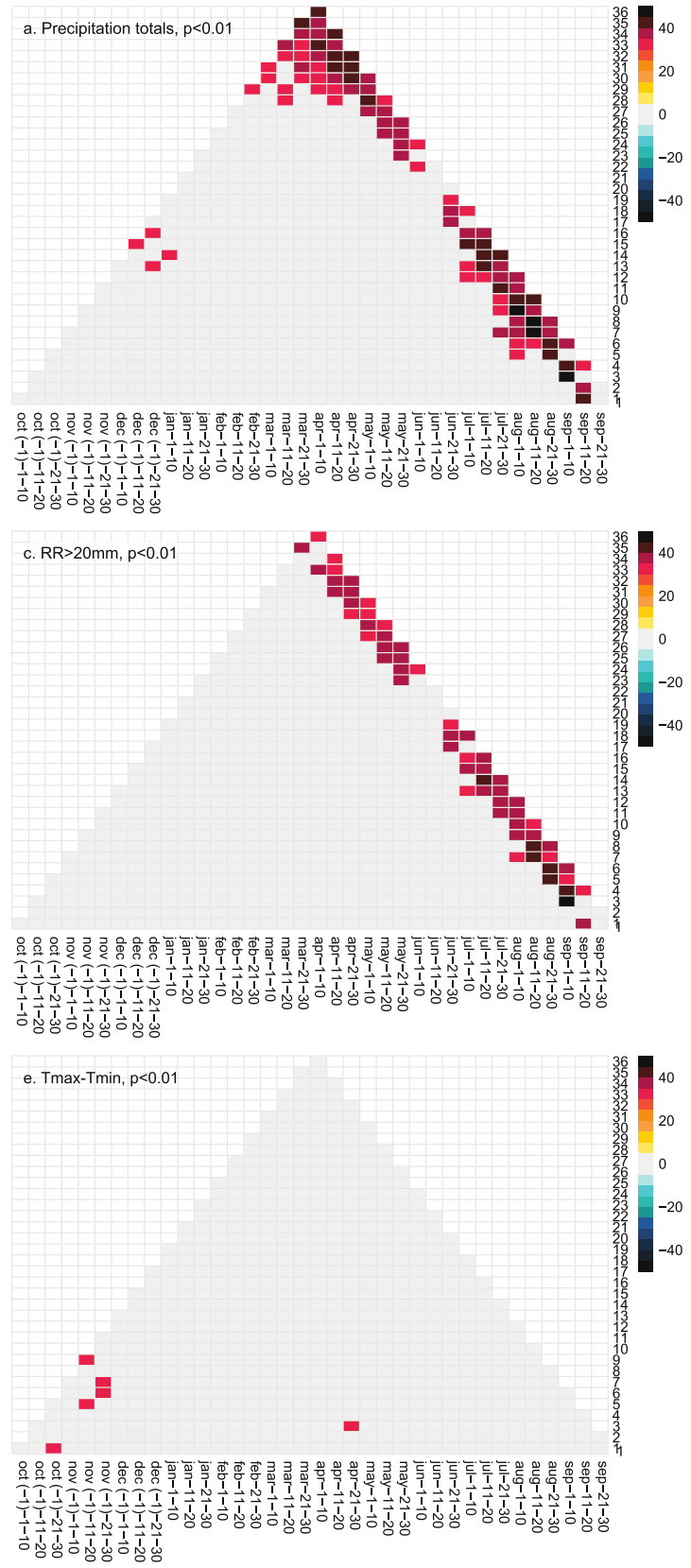

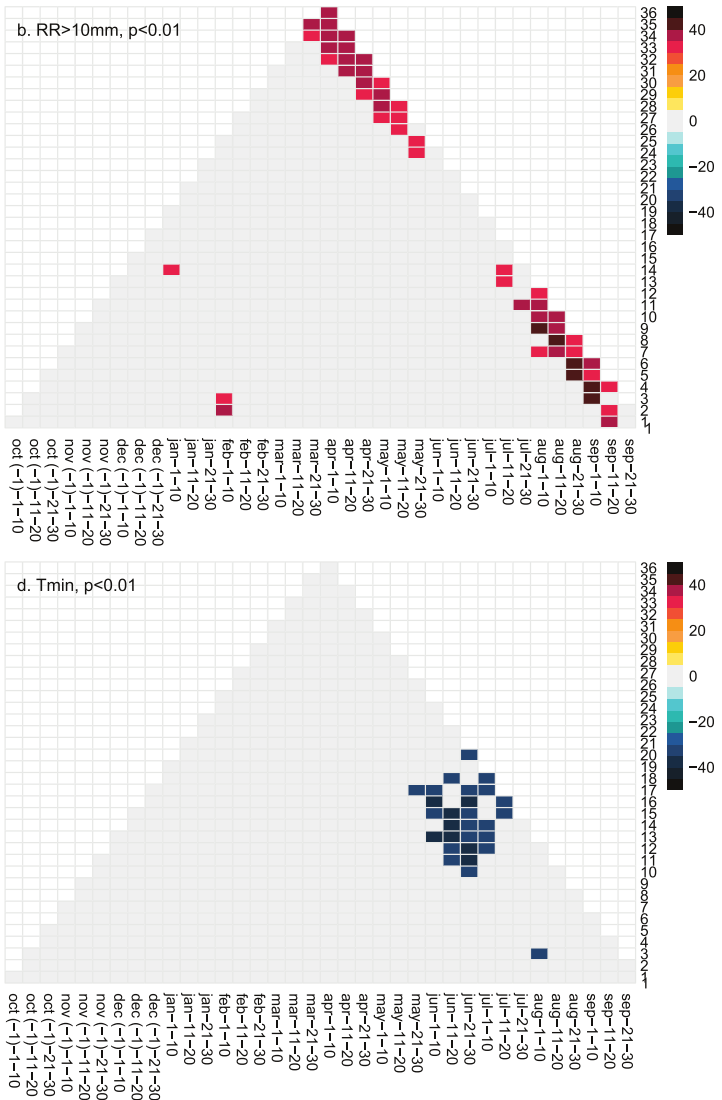

o

FIGURE 6. Correlations between R2 (reconstruction including only scars on compression wood) and meteorological covariables computed over 1 to 36 consecutive 10-day periods. [Colour figure can be viewed at wileyonlinelibrary.com]

whereby correlations suggest reduced rockfall activity during warm conditions in early spring to late summer (Figure $6 \mathrm{~d}$ ). Similarly, increasing temperature variations during autumn and early winter $(n-1)$ are synchronous, with an increase in impacts recorded in the tree-ring series during the subsequent growing season (Figure 6e). By contrast, no significant correlation was found between rockfall activity, maximum temperatures, or the number of freeze-thaw cycles irrespective of (1) the thresholds considered for frost events and (2) the number of 10-day periods included in the analysis.

Meteorological data which significantly correlated with R2 were then taken into consideration as independent variables during the multiple regression analyses. To limit the number of variables and potentially high multicollinearity in the model, potential regressors were selected using five correlation matrices, one for each meteorological parameter, computed for the variables showing the strongest correlations with rockfall activity (Figures $7 \mathrm{a}-\mathrm{e}$ ). In total, 10 variables (given in red in Figures 7 and 8) were retained, namely precipitation totals over 60 and
110 days centred around July $21-30$ and August 21-30, the number of rainfall events $>10 \mathrm{~mm}$ computed over 70 and 350 consecutive days centred around August 11-20 and March 21-30, the number of rainfall events $>20 \mathrm{~mm}$ for 60 (August 21-30) and 140 days (July 11-20), the minimum temperatures computed for 30 and 150 days centred around August 1-10 and July 11-20, as well as temperature variations computed over 30 (April 21-30) and 90 days (November, $n-1,11-20$ ).

On the basis of a stepwise selection procedure, four variables were retained in the more parsimonious model that minimizes the AIC with regression coefficients of $0.27,0.22,-0.14$, and 0.26 , respectively, for daily summer precipitation (computed over 60 days centred on August 21-30), the annual number of rainfall events $>10 \mathrm{~mm}$ (350 days, March 21-30), minimum temperatures (30 days, August 1-10), as well as temperature variations (90 days, November, $n-1,11-20)$. Each variable is significant at $p<0.05$. The VIFs, ranging between 1.02 for temperature variations and 1.3 for precipitation totals, show the absence of redundancy between predictor variables. The 


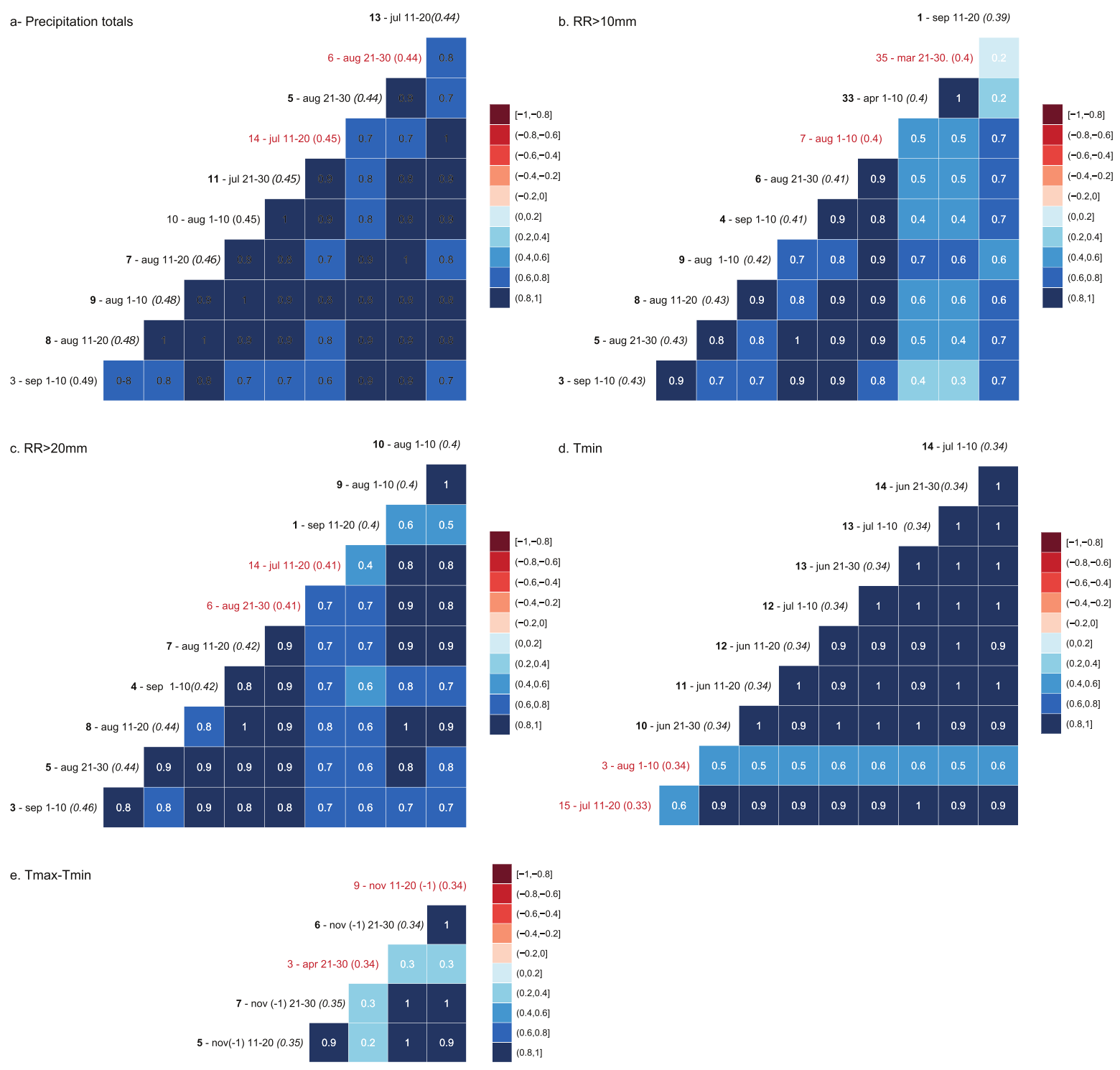

FIGURE 7. Correlation matrices computed between the precipitation totals (a), the number of summer rainfall events $>10 \mathrm{~mm}$ (b) and $>20 \mathrm{~mm}$ (c), minimal temperature (d) and temperature variations (e) using data from R2. Parameters given in red have later been included in the multiple regression model. [Colour figure can be viewed at wileyonlinelibrary.com]

model built on the basis of these variables explains $41 \%$ of the variance of rockfall activity, whereas the overall coefficient for predicted versus observed variance equals $r=0.65$ (Figures 10a and b). Boxplots in Figures 9a-d show the distribution of the meteorological variables included in the multiple regression model in relation to the different classes of rockfall activity. ANOVA shows significant differences $(p<0.05)$ between classes for summer daily precipitations (computed over 60 days centred around August) and the annual number of rainfall events $>10 \mathrm{~mm}$ day $^{-1}$ (350 days, March 21-30) (Figures 9a and $b$ ). Differences are not significant for minimum summer and fall temperatures (Figures 9c and d).

\section{Discussion}

\section{Novelty of the rockfall reconstruction approach}

Over the last decades, several approaches have been used in mountain regions to document the timing, frequency, and magnitude of rockfall events and to identify potential triggers of rockfall. In the source areas of rockfall, devices have been used to detect weathering such as extensometers or crackmeters
(Matsuoka, 2019; Weber et al., 2019), as well as microseismic or acoustic sensors (Amitrano et al., 2012) combined with micro-meteorological monitoring (Matsuoka, 2019). Similarly, rockfall frequency and failure have been estimated with traps (Sass, 2005), terrestrial laser scans (Rabatel et al., 2008; D'Amato et al., 2016), or remote digital time-lapse camera systems (Kellerer-Pirklbauer and Rieckh, 2016). Yet, and although these studies have clear merits in exploring rockfall initiation and triggers in great detail (Matsuoka, 2019), rockfall monitoring rarely exceeds a few years at single sites (Weber et al., 2019), thus precluding detetion of triggers, medium- to long-term drivers, triggers, or thresholds involved in rockfall processes and/or changes thereof. On forested slopes, the analysis of GDs in tree-ring series (Stoffel et al., 2005) has been used repeatedly to provide long-term, seasonally to annually resolved and - at least in theory - continuous records of past rockfall activity. Yet, so far, with the exception of Perret et al. (2006), Šilhán et al. (2011), or Zielonka and WrońskaWałach (2019), these proxy reconstructions have not yet investigated potential meteorological triggers of process activity. In addition, the latter studies did not - or only partly - account for non-stationarities in reconstructions related to (1) the continuous reduction in the number, diameter, and age (Šilhán 


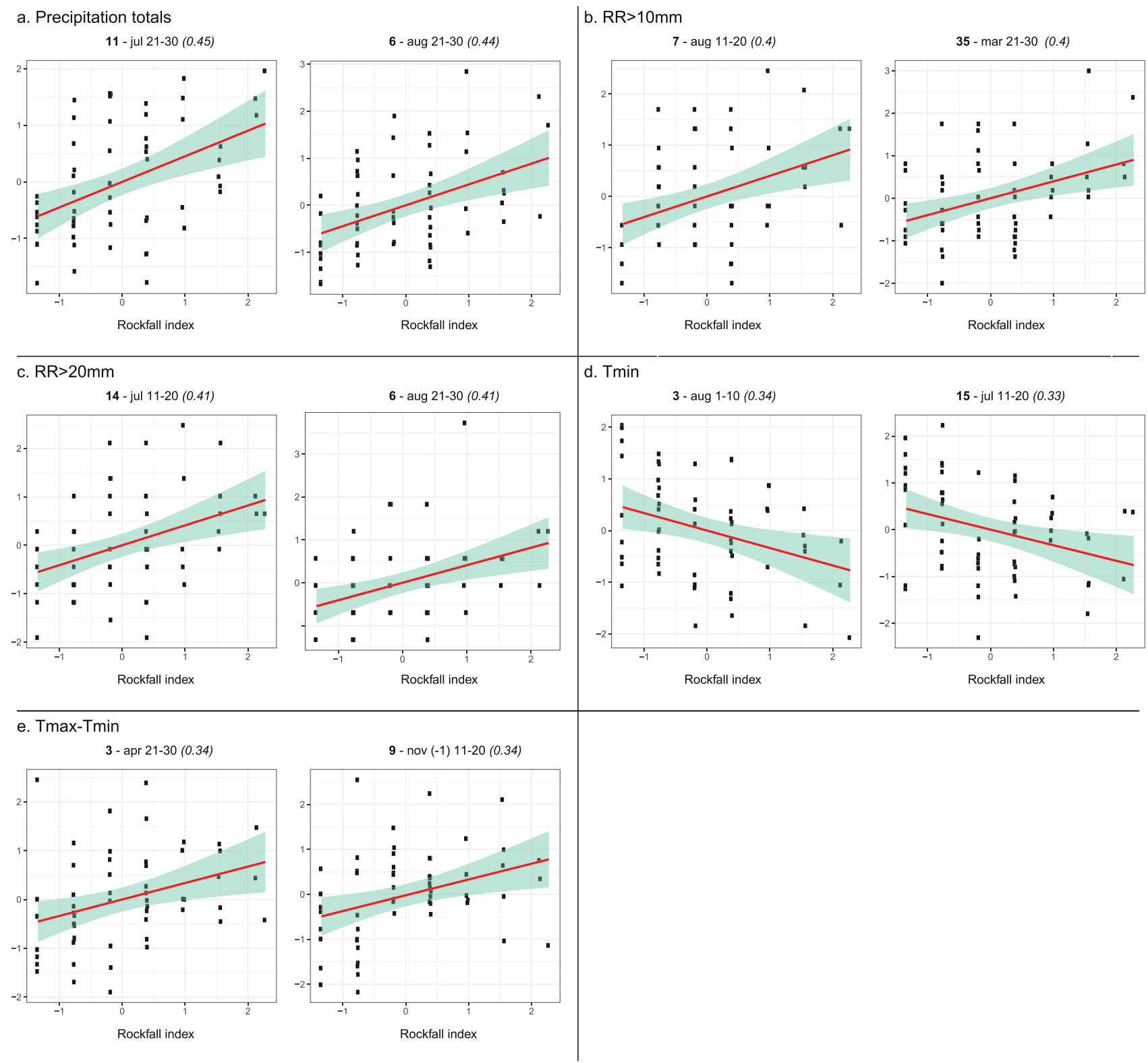

FIGURE 8. Correlations between R3 and the 10 meteorological variables retained in the multiple linear regression. [Colour figure can be viewed at wileyonlinelibrary.com]

et al., 2013) of trees impacted by rockfall as one goes back in time, (2) the decline in the number of potentially recordable GDs, (3) the complex detection of old, overhealed scars becoming virtually invisible on the stem surface (Trappmann and Stoffel, 2015), as well as (4) potential interferences between exogenous factors (e.g. climatic driver of tree growth, insect outbreaks affecting tree health) and rockfall activity. Indeed, Favillier et al. (2017b) evidenced that interferences between geomorphic process activity, ecological signals, and climatic conditions can leave similar signals in the tree-ring records, and that particular care needs to be taken when it comes to the separation of signals from noise. In particular, their study underlined the critical role of prolonged phases of growth suppression (GS). These signals have frequently been attributed to snow avalanche (or rockfall) activity, but were in fact induced by climatic extremes in the form of cold summers and/or prolonged droughts, thereby leading to a sustained decrease of radial growth (Battipaglia et al., 2009; Lévesque et al., 2013; George et al., 2015). To minimize these biases and assess the robustness of our reconstruction, we (1) selected trees in a protection forest planted at the turn of the 20th century so as to limit trends in rockfall activity related to a decreasing number of trees available for reconstruction. As a consequence, sample depth increased only slightly from 145 trees in 1918 to 179 trees in 2017 and from 175 to 179 trees between 1958 and 2017 (for which we also have meteorological records); (2) mapped all trees within the plot to optimize the selection of sampled trees and accurately estimate the evolution of the coefficient of interception over time (this high-resolution mapping allowed quantification of a limited evolution of the CIP as well as of the reliability of our reconstruction; we find that the selected trees theoretically intercept between 87 and $91 \%$ of all rockfall activity between 1958 and 2017); and (3) carefully analysed the influence of GD by creating two reconstructions including GS (R1) or only CW and injuries (R2) of the anomalies recorded in the tree-ring series. In the case of R2, we specifically excluded growth suppressions (GS) for reasons stated earlier. The complete absence of any statistically significant relationships between R1 and R2 (the latter includes only CW and injuries) suggests 

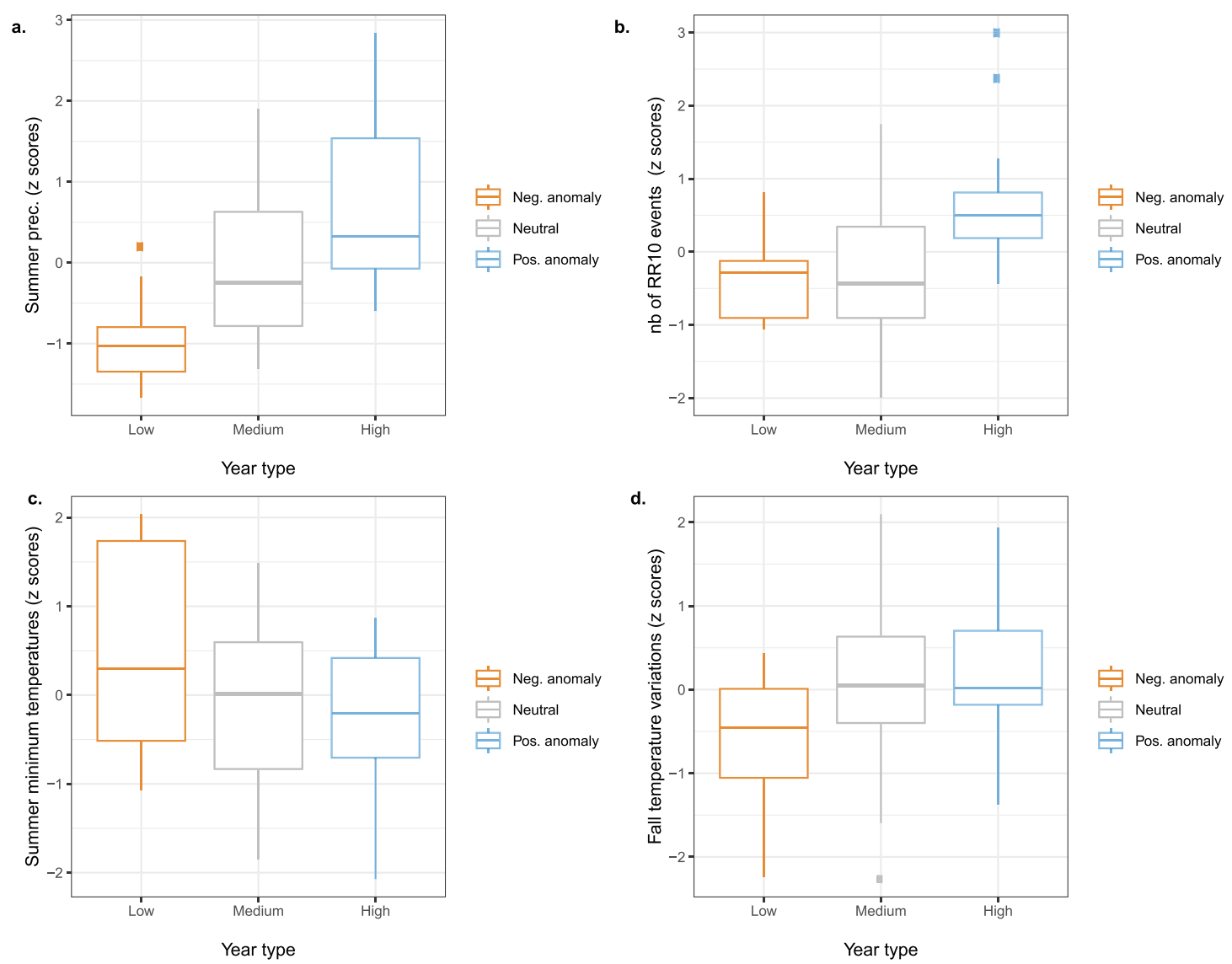

FIGURE 9. Boxplot of meteorological variables included in the multiple regression model [summer precipitations (a), number of rainfall events $>10 \mathrm{~mm}$ (b), summer minimum temperatures (c), and autumn temperature variations (d)] relative to years with low $(<-1 z$-score), medium (1 $>z-$ score $>-1)$, and high ( $>1 \mathrm{z}$-score) rockfall activity. [Colour figure can be viewed at wileyonlinelibrary.com]

that the two reconstructions portray different signals (and noise).

\section{Isolation of rockfall signals in tree-ring series}

A vast majority of past rockfall reconstructions included growth suppressions considered as indicators of decapitation or branch loss caused by rockfall impacts (Šilhán et al., 2011; Stoffel et al., 2011; Franco-Ramos et al., 2017), realized with Pinus trees, a species that is known for its sensitivity to droughts (Weber et al., 2007; Gruber et al., 2010). To date, and with the exception of excluding larch budmoth years and related GS as possible rockfall events (Stoffel et al., 2005; Schneuwly and
Stoffel, 2008a,b; Trappmann et al., 2014; Morel et al., 2015), no study has examined potential interferences between the geomorphic signal (related to rockfall) and other exogeneous factors such as insect outbreaks and/or climatic extremes (e.g. cold temperatures, drought) that are likely to cause GS (Favillier et al., 2017a). Here, the absence of a clear synchronicity between R1 and R2 pleads for the existence of different drivers of growth in trees. The comparison of recorded GD in reconstruction R1 - mostly GS - with meteorological series from the SAFRAN database failed to identify parameters considered as being most relevant in terms of driving rockfall dynamics (Luckman, 1976; Ishikawa et al., 2004; Matsuoka, 2008) (i.e. temperatures [minimal, mean, maximal, variations], freezethaw cycles or precipitation [totals and intensities]). Given the
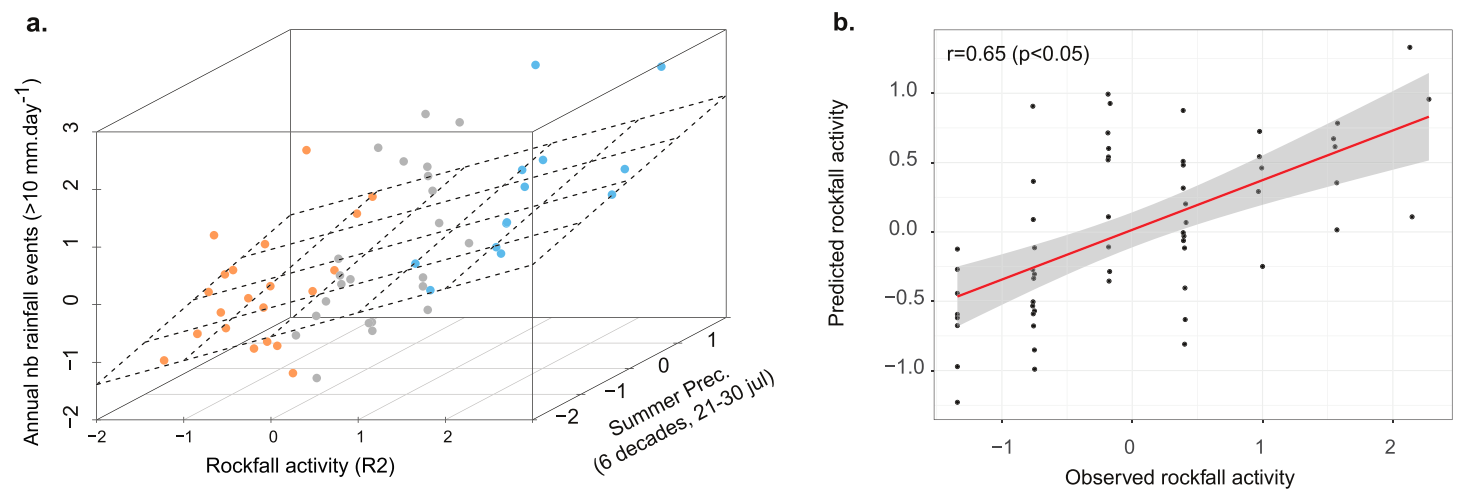

- Rockfall activ. $<-0.5 \bullet 0.5>$ Rockfall activ. $>-0.5 \bullet$ Rockfall activ. $>0.5$

FIGURE 10. Relation between rockfall activity, summer precipitations, and the number of rainfall events (a); observed annual number of rockfalls vs rockfall activity predicted by the multiple regression model (b). [Colour figure can be viewed at wileyonlinelibrary.com] 
sensitivity of $P$. nigra to drought, especially in Mediterranean environments (Martin-Benito et al., 2013), one can hypothesize that dry conditions could explain the high frequency of GS observed during, for example, the 2003 heatwave (Figures $5 \mathrm{~g}$ and h), in 1949 (Sanson and Pardé, 1950), and 1997 (Figures 5c and d). By contrast, above-average precipitation totals during the growing season in 1988 (Figure 5a), 2007 (Figure 5i), and especially 2001 (Figure 5e) do not allow us to validate the drought hypothesis further. Interestingly, the latter years - but also 2003 - coincide with years during which pine processionary moth (Thaumetopoea pityocampa) outbreaks have been recorded in the Southern French Alps (Bouhot-Delduc, 2005; Robinet et al., 2014; Li et al., 2015). As defoliation caused by caterpillars can cause a significant decrease in $P$. nigra radial growth over several years (Roques, 2015), we cannot exclude that the series of narrow rings observed in 2001, 2003, and 2007 could indeed be the result of moth outbreaks. In any case, however, and given (1) these potential interferences, (2) the difficulty of extracting a clear signal from R1, and (3) the absence of a correlation between R1 and R2 (where only GD that are clearly related to rockfall activity were included; i.e. injuries and compression wood), we encourage future studies to consider GS records very carefully before possibly including them in dendrogeomorphic reconstructions of rockfall activity.

\section{Meteorological drivers of rockfall activity at Valdrôme}

The comparison between R2 and meteorological parameters from the SAFRAN database demonstrates that precipitation totals and intense rainfall events were the main drivers of rockfall activity at Valdrôme over the period 1958-2017. At the same time, correlation matrices failed to identify the influence of freeze-thaw cycles and temperature variations on rockfall activity. In detail, our multiple regression model - designed to limit redundant variables - suggests that rockfall frequency at the site increases with above-average summer precipitation and intense rainfall, as these events probably raise water pressure in rock joints or can lead to the lubrification of joints (Matsuoka, 2019). Results obtained for the Valdrôme site are thus in line with those obtained by D'Amato et al. (2016) using LiDAR data from the calcareous Chartreuse Massif, located 90 km north of Valdrôme. In their study, D'Amato et al. (2016) reported that rockfall activity increased by a factor of 26 when mean rainfall intensity exceeded $5 \mathrm{~mm} \mathrm{~h}^{-1}$. Similarly, Delonca et al. (2014) showed that, on the basis of historical inventories, $15 \mathrm{~mm}$ of cumulative rainfall over 3 days doubled the probability of a rockfall occurring at their study site in Burgundy (France). In the Canadian Cordillera, Macciotta et al. (2015) revealed that over the period 1985-2013, a vast majority of rockfalls recorded by patrol cars, train crews, and maintenance crews along a railway section were driven by 3-day antecedent precipitation. Finally, our results are also consistent with tree-ring reconstructions from the Tatra Mountains, where cumulative precipitation in September and October $(n-1)$ and March $(n)$ were the main drivers of rockfall activity between 1950 and 2014 (Zielonka and WrońskaWałach, 2019). Our results, by contrast, differ from dendrogeomorphic reconstructions realized by Perret et al. (2006) and Šilhán et al. (2011) who could not evidence any unequivocal positive or negative correlations between rockfall rates and precipitation in the Flysch Carpathians and the Swiss Prealps. By contrast, no relation was found between reconstruction R2 and freeze-thaw cycles, although these have undoubtedly been demonstrated as a key driver of rockfall in a large body of monitoring literature (Matsuoka and Sakai, 1999;
Frayssines and Hantz, 2006; D'Amato et al., 2016; Matsuoka, 2019). Our analysis does not therefore differ fully from existing tree-ring reconstructions (1) reporting only weak, albeit significant positive correlations between reconstructed rockfall activity and numbers of days with temperature transitions around freezing (Šilhán et al., 2011; Zielonka and Wrońska-Wałach, 2019) or (2) attributing increasing decadal rockfall frequencies derived from tree-ring series during warm 20th-century winters to a more frequent occurrence of freezethaw cycles that would have helped weathering in a rock cliff located at $1250 \mathrm{~m}$ a.s.I. (Perret et al., 2006). Finally, and despite the high resolution of the meteorological dataset and the stringency of our reconstruction procedure, our multiple regression model can only account for $41 \%$ of the variance observed in rockfall activity. In other words, about $60 \%$ of the interannual rockfall variations are not explained by meteorological variables. This value is comparable to that reported by Perret et al. (2006) $\left(r^{2}=0.43\right.$ for temperatures over the 20th century). It exceeds the correlations obtained by Šilhán et al. (2011) between rockfall rates and different monthly, seasonal, and annual precipitation totals and the number of days during which temperature passed the zero-degree curtain $(r=0.3 ; 1931-2008)$. By contrast, the multiple linear regression model proposed by Zielonka and Wrońska-Wałach (2019) includes cumulative rainfall in March, June, July, September, and October, as well as average temperature in January and May, and explains 53\% of rockfall variance. Multiple causes have been discussed to explain the limited correlations obtained between rockfall reconstructions and meteorological co-variables. One reason certainly resides (1) in the quality of tree-ring reconstructions that can represent 'real' rockfall activity only partly at best and more generally still suffer from limitations in capturing process activity fully (Stoffel and Corona, 2014). In addition, (2) microclimatic variations and effects related to microtopography of cliffs and their impact on rockfall activity (Matsuoka and Sakai, 1999; Schneuwly and Stoffel, 2008b; Matsuoka, 2019) will not be covered fully by the meteorological datasets and the geomorphic approaches used in this study. Furthermore, (3) elevation differences between the meteorological stations and the rockwalls (Perret et al., 2006; Zielonka and Wrońska-Wałach, 2019) cannot obviously be excluded at Valdrôme. By contrast, the impacts of earthquake shaking, susceptible to result in abundant co-seismic rockfall activity close to the epicentre location $(\approx 15 \mathrm{~km}$, for a magnitude $M=5-7$; Stoffel et al., 2019), cannot be completely ruled out but its effect on rockfall at Valdrôme is probably very limited as the region is considered to have very low seismicity according to information provided by French National Territory (map available at https://www.georisques.gouv. fr/articles/zonage-sismique-de-la-france; accessed 3 December 2019).

\section{Conclusions}

Over the last two decades, several dendrogeomorphic studies have reconstructed rockfall activity in mountainous regions worldwide. Paradoxically, reconstructed rockfall activity has only rarely been compared with climatic data to identify potential meteorological triggers of process activity. In this paper, we used highly resolved mapping of a protection forest planted at the turn of the 20th century which allowed minimizing potential biases and precisely quantifying uncertainties related to decreasing sample size back in time. In methodological terms, we demonstrate that the inclusion of growth suppression as a signal of past rockfall activity is not recommended in Pinus $s p$. trees as it will result in very limited synchronicity between reconstructions developed in all GDs (R1) and those where GS 
events are excluded (R2). Likewise, we were unable to find a clear meteorological trigger in R1, which calls for the inclusion of injures and compression wood only in future dendrogeomorphic studies focusing on pine trees. Relationships between reconstruction R2 and meteorological variables computed over 10 to 360 consecutive days enabled identification of summer precipitation totals and annual number of rainfall events $>10 \mathrm{~mm}$ as the main drivers of rockfall activity at Valdrôme. Despite the stringency of the procedure developed here and the high spatio-temporal resolution of the SAFRAN database, the correlation between rockfall activity and meteorological records remains comparable to those reported in previous tree-ring reconstructions. We explain this limited correlation by the multiplicity of factors susceptible to trigger rockfall events. In that sense, we plead for more systematic coupling between dendrogeomorphic studies and rockfall as well as microclimatic monitoring of sites in the future.

Acknowledgements-This research benefitted from the support of the national C2ROP project supported by MEDDE, the Ministry of Ecology, Sustainable Development and Energy (http://www.c2rop.fr/) and of Labex OSUG@2020 and within the CDP-Trajectories framework, of the French National Research Agency (ANR-15IDEX-02).

\section{Conflict of Interest Statement}

No conflicts of interest are declared.

\section{Data Availability Statement}

Research data are not shared.

\section{References}

AlestaloJ. 1971. Dendrochronological interpretation of geomorphic processes. 1105

AmitranoD, GruberS, GirardL. 2012. Evidence of frost-cracking inferred from acoustic emissions in a high-alpine rock-wall. Earth and Planetary Science Letters 341-344: 86-93. https://doi.org/10.1016/j. epsl.2012.06.014

AndréM-F. 1997. Holocene rockwall retreat in Svalbard: a triple-rate evolution. Earth Surface Processes and Landforms 22: 423-440. https://doi.org/10.1002/(SICI)1096-9837(199705)22:5<423::AIDESP706>3.0.CO;2-6

BarnikelF. 2004. The value of historical documents for hazard zone mapping. Natural Hazards and Earth System Sciences 4: 599-613. https://doi.org/10.5194/nhess-4-599-2004

BattipagliaG, SaurerM, CherubiniP, SiegwolfRTW, CotrufoMF. 2009. Tree rings indicate different drought resistance of a native (Abies alba Mill.) and a nonnative (Picea abies (L.) Karst.) species co-occurring at a dry site in Southern Italy. Forest Ecology and Management 257: 820-828. https://doi.org/10.1016/j.foreco.2008.10.015

BertiM, MartinaMLV, FranceschiniS, PignoneS, SimoniA, PizzioloM. 2012. Probabilistic rainfall thresholds for landslide occurrence using a Bayesian approach. Journal of Geophysical Research - Earth Surface 117: F04006. https://doi.org/10.1029/2012JF002367

BollschweilerM, StoffelM, SchneuwlyDM, BourquiK. 2008. Traumatic resin ducts in Larix decidua stems impacted by debris flows. Tree Physiology 28: 255-263. https://doi.org/10.1093/treephys/28.2.255

Bouhot-DelducL. 2005. Dynamique des populations de la processionnaire du pin et extension de son aire de colonisation de 1981 à 2004 en France (Bilan de la santé des forets en 2004). Ministère de l'Agriculture, de l'Alimentation, de la Peche et de la Ruralité.

BräkerOU. 2002. Measuring and data processing in tree-ring research a methodological introduction. Dendrochronologia 20: 203-216. https://doi.org/10.1078/1125-7865-00017
CoronaC, TrappmannD, StoffelM. 2013. Parameterization of rockfall source areas and magnitudes with ecological recorders: when disturbances in trees serve the calibration and validation of simulation runs. Geomorphology 202: 33-42. https://doi.org/10.1016/j. geomorph.2013.02.001

CoronaC, Lopez-Saez], FavillierA, MainieriR, EckertN, TrappmannD, StoffelM, BourrierF, BergerF. 2017. Modeling rockfall frequency and bounce height from three-dimensional simulation process models and growth disturbances in submontane broadleaved trees. Geomorphology 281: 66-77. https://doi.org/10.1016/j. geomorph.2016.12.019

CrudenDM, VarnesDJ. 1996. Landslides: investigation and mitigation. Transportation Research Board Special Report.

D'AmatoJ, HantzD, GuerinA, JaboyedoffM, BailletL, MariscalA. 2016. Influence of meteorological factors on rockfall occurrence in a middle mountain limestone cliff. Natural Hazards and Earth System Sciences 16: 719-735. https://doi.org/10.5194/nhess-16-719-2016

DeloncaA, GunzburgerY, VerdelT. 2014. Statistical correlation between meteorological and rockfall databases. Natural Hazards and Earth System Sciences 14: 1953-1964. https://doi.org/10.5194/nhess-141953-2014

DorrenL, BergerF, JonssonM, KrautblatterM, MölkM, StoffelM, WehrliA. 2007. State of the art in rockfall - forest interactions. Schweizerische Zeitschrift für Forstwesen 158: 128-141. https://doi.org/10.3188/ szf.2007.0128

DunlopS. 2010. Rockslides in a changing climate: establishing relationships between meteorological conditions and rockslides in southwestern Norway for the purposes of developing a hazard forecast system. MS thesis, Queen's University, Canada.

DurandY, GiraudG, LaternserM, EtcheversP, MérindolL, LesaffreB. 2009a. Reanalysis of 47 years of climate in the French Alps (19582005): climatology and trends for snow cover. Journal of Applied Meteorology and Climatology 48: 2487-2512. https://doi.org/10.1175/ 2009JAMC1810.1

DurandY, LaternserM, GiraudG, EtcheversP, LesaffreB, MérindolL. 2009b. Reanalysis of $44 \mathrm{yr}$ of climate in the French Alps (19582002): methodology, model validation, climatology, and trends for air temperature and precipitation. Journal of Applied Meteorology and Climatology 48: 429-449. https://doi.org/10.1175/ 2008JAMC1808.1

Dussauge-PeisserC, HelmstetterA, GrassoJ-R, HantzD, DesvarreuxP, JeanninM, GiraudA. 2002. Probabilistic approach to rock fall hazard assessment: potential of historical data analysis. Natural Hazards and Earth System Sciences 2: 15-26. https://doi.org/10.5194/nhess-2-152002

FavillierA, GuilletS, MorelP, CoronaC, Lopez-SaezJ, EckertN, Ballesteros CánovasJA, PeiryJ-L, StoffelM. 2017a. Disentangling the impacts of exogenous disturbances on forest stands to assess multi-centennial tree-ring reconstructions of avalanche activity in the upper Goms Valley (Canton of Valais, Switzerland). Quaternary Geochronology 42: 89-104. https://doi.org/10.1016/j. quageo.2017.09.001

FavillierA, MainieriR, SaezJL, BergerF, StoffelM, CoronaC. 2017b. Dendrogeomorphic assessment of rockfall recurrence intervals at Saint Paul de Varces, Western French Alps. Géomorphologie: relief, processus, environnement 23: 109-119. https://doi.org/10.4000/ geomorphologie.11681

Franco-RamosO, StoffelM, Vázquez-SelemL. 2017. Tree-ring based reconstruction of rockfalls at Cofre de Perote volcano, Mexico. Geomorphology 290: 142-152. https://doi.org/10.1016/j. geomorph.2017.04.003

FrayssinesM, HantzD. 2006. Failure mechanisms and triggering factors in calcareous cliffs of the Subalpine Ranges (French Alps). Engineering Geology 86: 256-270. https://doi.org/10.1016/j. enggeo.2006.05.009

GeorgeJ-P, SchuelerS, Karanitsch-AckerlS, MayerK, KlumppRT, GrabnerM. 2015. Inter- and intra-specific variation in drought sensitivity in Abies spec. and its relation to wood density and growth traits. Agricultural and Forest Meteorology 214-215: 430-443. https://doi. org/10.1016/j.agrformet.2015.08.268

GruberA, StroblS, VeitB, OberhuberW. 2010. Impact of drought on the temporal dynamics of wood formation in Pinus sylvestris. Tree Physiology 30: 490-501. https://doi.org/10.1093/treephys/tpq003 
GunzburgerY, Merrien-SoukatchoffV, GuglielmiY. 2005. Influence of daily surface temperature fluctuations on rock slope stability: case study of the Rochers de Valabres slope (France). International Journal of Rock Mechanics and Mining Sciences 42: 331-349. https://doi. org/10.1016/j.ijrmms.2004.11.003

GuzzettiF, TonelliG. 2004. Information system on hydrological and geomorphological catastrophes in Italy (SICI): a tool for managing landslide and flood hazards. Natural Hazards and Earth System Sciences 4: 213-232. https://doi.org/10.5194/nhess-4-213-2004

GuzzettiF, CarraraA, CardinaliM, ReichenbachP. 1999. Landslide hazard evaluation: a review of current techniques and their application in a multi-scale study, Central Italy. Geomorphology 31: 181-216. https://doi.org/10.1016/S0169-555X(99)00078-1

HaleAJ, CalderES, LoughlinSC, WadgeG, RyanGA. 2009. Modelling the lava dome extruded at Soufrière Hills Volcano, Montserrat, August 2005-May 2006. Journal of Volcanology and Geothermal Research 187: 69-84. https://doi.org/10.1016/j.jvolgeores.2009.08.014

HantzD, VengeonJM, Dussauge-PeisserC. 2003. An historical, geomechanical and probabilistic approach to rock-fall hazard assessment. Natural Hazards and Earth System Sciences 3: 693-701. https://doi.org/10.5194/nhess-3-693-2003

HeimA. 1931. Bergsturz und Menschenleben. https://doi.org/10.5169/ SEALS-9840

HuggelC, ClagueJJ, KorupO. 2012. Is climate change responsible for changing landslide activity in high mountains?Earth Surface Processes and Landforms 37: 77-91. https://doi.org/10.1002/esp.2223

IbsenM-L, BrunsdenD. 1996. The nature, use and problems of historical archives for the temporal occurrence of landslides, with specific reference to the south coast of Britain, Ventnor, Isle of Wight. Geomorphology 15: 241-258. https://doi.org/10.1016/0169-555X(95)00073-E

IlincaV. 2009. Rockfall hazard assessment. Case study: Lotru Valley and Olt Gorge. Revista de geomorfologie 11: 101-108.

IshikawaM, KurashigeY, HirakawaK. 2004. Analysis of crack movements observed in an alpine bedrock cliff. Earth Surface Processes and Landforms 29: 883-891. https://doi.org/10.1002/esp.1076

KeeferDK. 2002. Investigating landslides caused by earthquakes - a historical review. Surveys in Geophysics 23: 473-510. https://doi. org/10.1023/A:1021274710840

Kellerer-PirklbauerA, RieckhM. 2016. Monitoring nourishment processes in the rooting zone of an active rock glacier in an alpine environment. Zeitschrift für Geomorphologie Supplementband 60: 99-121. https://doi.org/10.1127/zfg_suppl/2016/00245

LarsonPR. 1994. The vascular cambium: development and structure. Springer: Berlin.

LévesqueM, SaurerM, SiegwolfR, EilmannB, BrangP, BugmannH, RiglingA. 2013. Drought response of five conifer species under contrasting water availability suggests high vulnerability of Norway spruce and European larch. Global Change Biology 19: 3184-3199. https://doi.org/10.1111/gcb.12268

LiS, DaudinJJ, PiouD, RobinetC, JactelH. 2015. Periodicity and synchrony of pine processionary moth outbreaks in France. Forest Ecology and Management 354: 309-317. https://doi.org/10.1016/j. foreco.2015.05.023

LuckmanBH. 1976. Rockfalls and rockfall inventory data: some observations from surprise valley, Jasper National Park, Canada. Earth Surface Processes 1: 287-298. https://doi.org/10.1002/ esp.3290010309

MacciottaR, MartinCD, EdwardsT, CrudenDM, KeeganT. 2015. Quantifying weather conditions for rock fall hazard management. Georisk: Assessment and Management of Risk for Engineered Systems and Geohazards 9: 171-186. https://doi.org/10.1080/ 17499518.2015.1061673

MainieriR, Lopez-SaezJ, CoronaC, StoffelM, BourrierF, EckertN. 2019. Assessment of the recurrence intervals of rockfall through dendrogeomorphology and counting scar approach: a comparative study in a mixed forest stand from the Vercors massif (French Alps). Geomorphology 340: 160-171. https://doi.org/10.1016/j. geomorph.2019.05.005

MalamudBD, TurcotteDL, GuzzettiF, ReichenbachP. 2004. Landslide inventories and their statistical properties. Earth Surface Processes and Landforms 29: 687-711. https://doi.org/10.1002/esp.1064

Martin-BenitoD, BeeckmanH, Cañellasl. 2013. Influence of drought on tree rings and tracheid features of Pinus nigra and Pinus sylvestris in a mesic Mediterranean forest. European Journal of Forest Research 132: 33-45. https://doi.org/10.1007/s10342-012-0652-3

MatsuokaN. 2008. Frost weathering and rockwall erosion in the southeastern Swiss Alps: long-term (1994-2006) observations. Geomorphology 99: 353-368. https://doi.org/10.1016/j. geomorph.2007.11.013

MatsuokaN. 2019. A multi-method monitoring of timing, magnitude and origin of rockfall activity in the Japanese Alps. Geomorphology 336: 65-76. https://doi.org/10.1016/j.geomorph.2019.03.023

MatsuokaN, SakaiH. 1999. Rockfall activity from an alpine cliff during thawing periods. Geomorphology 28: 309-328. https://doi.org/ 10.1016/S0169-555X(98)00116-0

MichoudC, DerronM-H, HortonP, JaboyedoffM, BaillifardF-J, LoyeA, NicoletP, PedrazziniA, QueyrelA. 2012. Rockfall hazard and risk assessments along roads at a regional scale: example in Swiss Alps. Natural Hazards and Earth System Sciences 12: 615-629. https:// doi.org/10.5194/nhess-12-615-2012

MorelP, TrappmannD, CoronaC, StoffelM. 2015. Defining sample size and sampling strategy for dendrogeomorphic rockfall reconstructions. Geomorphology 236: 79-89. https://doi.org/10.1016/j. geomorph.2015.02.017

MoyaJ, CorominasJ, Pérez ArcasJ, BaezaC. 2010. Tree-ring based assessment of rockfall frequency on talus slopes at Solà d'Andorra, Eastern Pyrenees. Geomorphology 118: 393-408. https://doi.org/ 10.1016/j.geomorph.2010.02.007

MüllerL. 1964. The rock slide in the Vajont Valley. Rock Mechanics and Engineering Geology 2: 148-212.

PerretS, StoffelM, KienholzH. 2006. Spatial and temporal rockfall activity in a forest stand in the Swiss Prealps - a dendrogeomorphological case study. Geomorphology 74: 219-231. https://doi.org/10.1016/j. geomorph.2005.08.009

RabatelA, DelineP, JailletS, RavanelL. 2008. Rock falls in high-alpine rock walls quantified by terrestrial lidar measurements: a case study in the Mont Blanc area. Geophysical Research Letters 35. https:// doi.org/10.1029/2008GL033424

RappA. 1960. Recent development of mountain slopes in Kärkevagge and Surroundings, Northern Scandinavia. Geografiska Annaler 42: 65-200. https://doi.org/10.1080/20014422.1960.11880942

RobinetC, Rousselet), RoquesA. 2014. Potential spread of the pine processionary moth in France: preliminary results from a simulation model and future challenges. Annals of Forest Science 71: 149-160. https://doi.org/10.1007/s13595-013-0287-7

RoquesA (ed). 2015. Processionary moths and climate change: an update. Springer: Dordrecht.

RosserNJ, PetleyDN, LimM, DunningSA, AllisonRJ. 2005. Terrestrial laser scanning for monitoring the process of hard rock coastal cliff erosion. Quarterly Journal of Engineering Geology and Hydrogeology 38: 363-375. https://doi.org/10.1144/1470-9236/05-008

SachsT. 1991. Pattern formation in plant tissues. Cambridge University Press: Cambridge.

SansonJ, PardéM. 1950. La sécheresse des années 1942-49 en France. rga 38, 369-404. https://doi.org/10.3406/rga.1950.4042

SassO. 2005. Temporal variability of rockfall in the Bavarian Alps, Germany. Arctic, Antarctic, and Alpine Research 37: 564-573.

SassO, OberlechnerM. 2012. Is climate change causing increased rockfall frequency in Austria?Natural Hazards and Earth System Sciences 12: 3209-3216. https://doi.org/10.5194/nhess-12-3209-2012

SazidM. 2019. Analysis of rockfall hazards along NH-15: a case study of Al-Hada road. Geotechnical Engineering 10. https://doi.org/ 10.1186/s40703-019-0097-3

SchneuwlyDM, StoffelM. 2008a. Spatial analysis of rockfall activity, bounce heights and geomorphic changes over the last 50 years - a case study using dendrogeomorphology. Geomorphology 102: 522-531. https://doi.org/10.1016/j.geomorph.2008.05.043

SchneuwlyDM, StoffelM. 2008b. Tree-ring based reconstruction of the seasonal timing, major events and origin of rockfall on a case-study slope in the Swiss Alps. Natural Hazards and Earth System Sciences 8: 203-211. https://doi.org/10.5194/nhess-8-203-2008

SchneuwlyDM, StoffelM, BollschweilerM. 2009a. Formation and spread of callus tissue and tangential rows of resin ducts in Larix decidua and Picea abies following rockfall impacts. Tree Physiology 29: 281-289. https://doi.org/10.1093/treephys/tpn026 
SchneuwlyDM, StoffelM, DorrenLKA, BergerF. 2009b. Three-dimensional analysis of the anatomical growth response of European conifers to mechanical disturbance. Tree Physiology 29: 1247-1257. https://doi.org/10.1093/treephys/tpp056

ŠilhánK, BrázdilR, PánekT, DobrovolnýP, KašičkováL, TolaszR, TurskýO, VáclavekM. 2011. Evaluation of meteorological controls of reconstructed rockfall activity in the Czech Flysch Carpathians. Earth Surface Processes and Landforms 36: 1898-1909. https://doi. org/10.1002/esp.2211

ŠilhánK, PánekT, HradeckýJ. 2013. Implications of spatial distribution of rockfall reconstructed by dendrogeomorphological methods. Natural Hazards and Earth System Sciences 13: 1817-1826. https://doi. org/10.5194/nhess-13-1817-2013

StoffelM, BollschweilerM. 2008. Tree-ring analysis in natural hazards research - an overview. Natural Hazards and Earth System Sciences 8: 187-202. https://doi.org/10.5194/nhess-8-187-2008

StoffelM, CoronaC. 2014. Dendroecological dating of geomorphic disturbance in trees. Tree-Ring Research 70: 3-20. https://doi.org/ 10.3959/1536-1098-70.1.3

StoffelM, HuggelC. 2012. Effects of climate change on mass movements in mountain environments. Progress in Physical Geography: Earth and Environment 36: 421-439. https://doi.org/10.1177/ 0309133312441010

StoffelM, PerretS. 2006. Reconstructing past rockfall activity with tree rings: some methodological considerations. Dendrochronologia 24 1-15. https://doi.org/10.1016/j.dendro.2006.04.001

StoffelM, SchneuwlyD, BollschweilerM, Lièvrel, DelaloyeR, MyintM, MonbaronM. 2005. Analyzing rockfall activity (1600-2002) in a protection forest-a case study using dendrogeomorphology. Geomor phology 68: 224-241. https://doi.org/10.1016/j. geomorph.2004.11.017

StoffelM, WehrliA, KühneR, DorrenLKA, PerretS, KienholzH. 2006. Assessing the protective effect of mountain forests against rockfall using a 3D simulation model. Forest Ecology and Management 225 113-122. https://doi.org/10.1016/j.foreco.2005.12.030

StoffelM, BollschweilerM, Vázquez-SelemL, Franco-RamosO, PalaciosD. 2011. Dendrogeomorphic dating of rockfalls on lowlatitude, high-elevation slopes: Rodadero, Iztaccíhuatl volcano, Mexico. Earth Surface Processes and Landforms 36: 1209-1217. https://doi.org/10.1002/esp.2146

StoffelM, ButlerDR, CoronaC. 2013. Mass movements and tree rings: a guide to dendrogeomorphic field sampling and dating. Geomorphology 200: 106-120. https://doi.org/10.1016/j.geomorph.2012.12.017
StoffelM, Ballesteros CánovasJA, LuckmanBH, CastellerA, VillalbaR. 2019. Tree-ring correlations suggest links between moderate earthquakes and distant rockfalls in the Patagonian Cordillera. Scientific Reports 9: 1-9. https://doi.org/10.1038/s41598-019-48530-5

TerzaghiK. 1962. Stability of steep slopes on hard unweathered rock. Géotechnique 12: 251-270. https://doi.org/10.1680/ geot.1962.12.4.251

TrappmannD, StoffelM. 2015. Visual dating of rockfall scars in Larix decidua trees. Geomorphology 245: 62-72. https://doi.org/10.1016/j. geomorph.2015.04.030

TrappmannD, CoronaC, StoffelM. 2013. Rolling stones and tree rings: a state of research on dendrogeomorphic reconstructions of rockfall. Progress in Physical Geography 37: 701-716. https://doi.org/ 10.1177/0309133313506451

TrappmannD, StoffelM, CoronaC. 2014. Achieving a more realistic assessment of rockfall hazards by coupling three-dimensional process models and field-based tree-ring data. Earth Surface Processes and Landforms 39: 1866-1875. https://doi.org/10.1002/esp.3580

VillalbaR, VeblenTT. 1997. Improving estimates of total tree ages based on increment core samples. É coscience 4: 534-542. https://doi.org/ 10.1080/11956860.1997.11682433

WeberP, BugmannH, RiglingA. 2007. Radial growth responses to drought of Pinus sylvestris and Quercus pubescens in an inner-Alpine dry valley. Journal of Vegetation Science 18: 777-792. https://doi.org/10.1111/j.1654-1103.2007.tb02594.x

WeberS, BeutelJ, FornoRD, GeigerA, GruberS, GsellT, HaslerA, KellerM, LimR, LimpachP, MeyerM, Talzil, ThieleL, TschudinC, VieliA, Vonder MühIID, YücelM. 2019. A decade of detailed observations (2008-2018) in steep bedrock permafrost at the Matterhorn Hörnligrat (Zermatt, $\mathrm{CH}$ ). Earth System Science Data 11: 1203-1237. https://doi.org/10.5194/essd-11-1203-2019

WieczorekGF, JägerS. 1996. Triggering mechanisms and depositiona rates of postglacial slope-movement processes in the Yosemite Valley, California. Geomorphology 15: 17-31. https://doi.org/10.1016/ 0169-555X(95)00112-I

ZielonkaA, Wrońska-WałachD. 2019. Can we distinguish meteorological conditions associated with rockfall activity using dendrochronological analysis? An example from the Tatra Mountains (Southern Poland). Science of the Total Environment 662: 422-433. https:// doi.org/10.1016/j.scitotenv.2019.01.243 